\title{
Universal Control of Permanent Magnet Synchronous Motors with Uncertain Dynamics
}

\author{
by
}

\author{
Rishil Lakhe
}

A thesis submitted to the Faculty of Graduate and Postdoctoral Affairs in partial fulfillment of the requirements for the degree of

Master of Applied Science in

Electrical and Computer Engineering

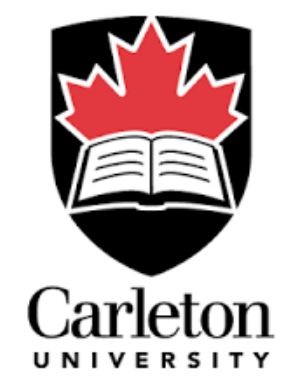

Faculty of Engineering and Design

Department of Electronics

Carleton University

Ottawa, Ontario, Canada

Copyright (C) 2020 Rishil Lakhe 


\section{Abstract}

Permanent magnet synchronous motors (PMSMs) are used in various industrial applications and many theoretical advances have been achieved in the domain of PMSM control. However, more research is needed in the area of self-commissioning drives which can operate with very minimum information of motor parameters. This thesis focuses on the universal control design of PMSMs and uses two control methods: conventional field-oriented vector control and simplified control. In vector control, the classical proportional-integral (PI) controller is used to control the $d-q$ axis currents and speed of the PMSM. The main aim is to determine the PI controller gains using an empirical study and generalized mathematical expressions. In vector control, these equations use power ratings, while in simplified control, the product of number of pole pairs and flux linkage is used for automatic gain calculation. Validation of both the proposed control strategies is done in MATLAB/Simulink, and satisfactory results are obtained. 


\section{Acknowledgements}

I would like to express my heartfelt gratitude to my supervisor Prof. Hicham Chaoui without whom this research would have been impossible. I thank him for giving me the opportunity to complete my thesis through his constant support and guidance. His encouragement and ideas have helped a lot to shape this research into what it is now today.

I would also like to give special thanks to Mohamad Alzayed in helping me with my conceptual doubts. Specially, I really appreciate his help in improving the MATLAB simulation files for better research output.

I also acknowledge the graciousness of the Department of Electronics and Prof. Chaoui for the financial assistance in the form of TA and RA funding.

Last but not the least, I would like to express my deepest gratitude to my family, especially my mother, for her unconditional love and caring, and my grandmother, who follows every steps of mine, I believe, from heaven. I would finally appreciate the encouragement and support given by my grandfather to overcome all the challenges and succeed in life. 


\section{Table of Contents}

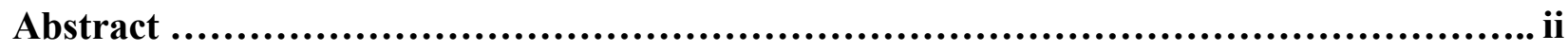

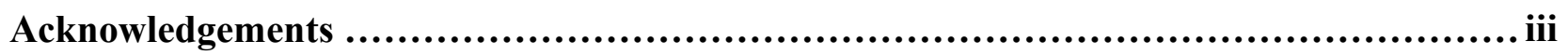

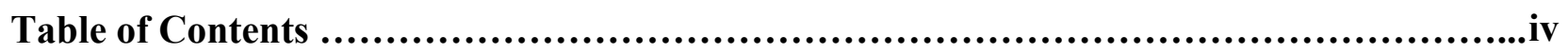

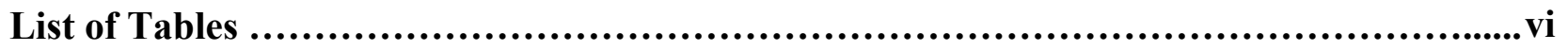

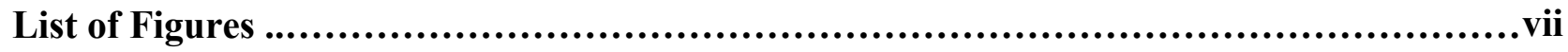

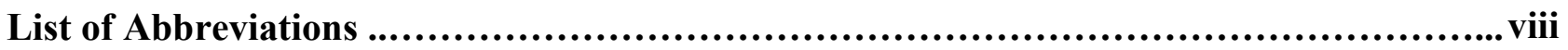

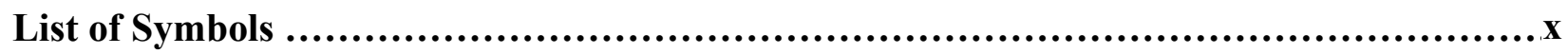

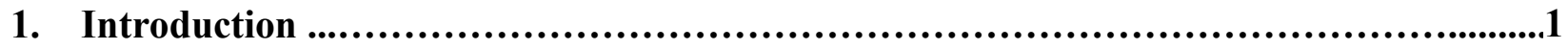

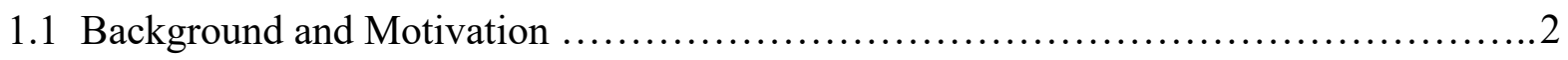

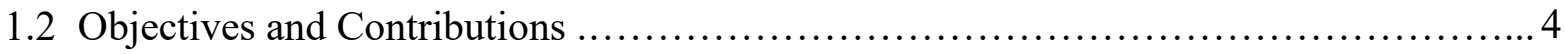

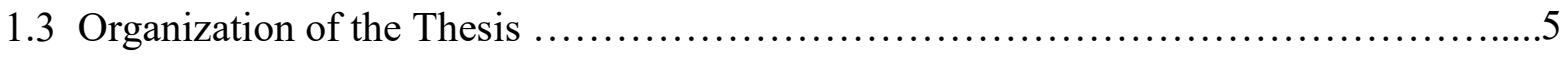

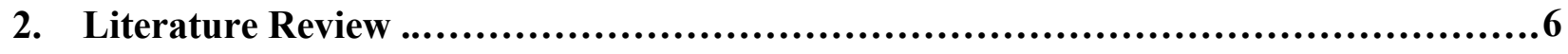

2.1 Scalar Control Method .........................................................

2.2 Vector Control Methods .............................................................. 7

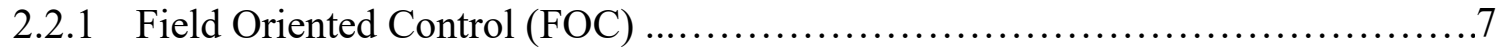

2.2.2 Voltage Vector Control (VVC) ...........................................11

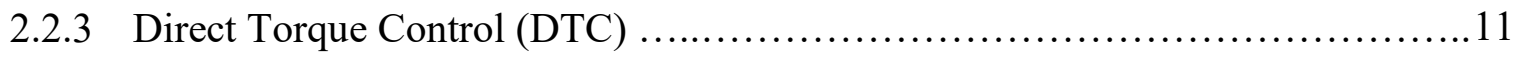

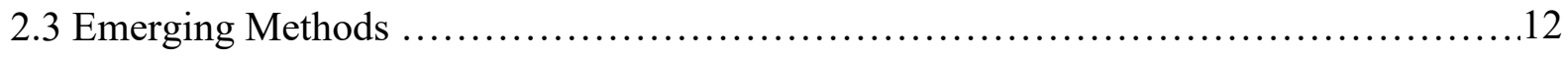

2.3.1 Fuzzy Logic Based Control .................................................13

2.3.2 Artificial Neural Network Based Control ....................................14 


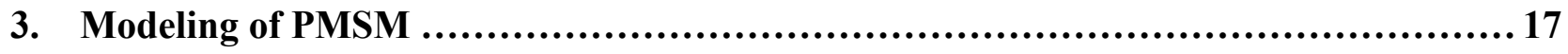

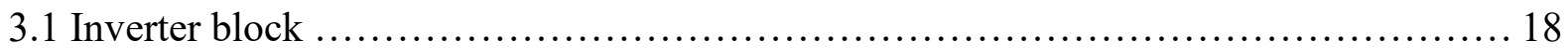

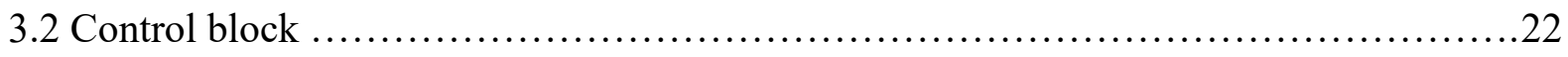

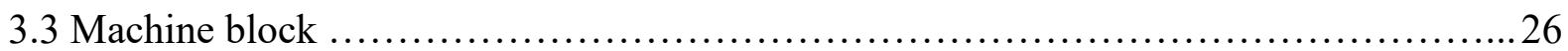

4. Proposed Universal Control Strategies ................................................. 28

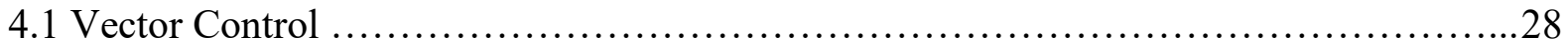

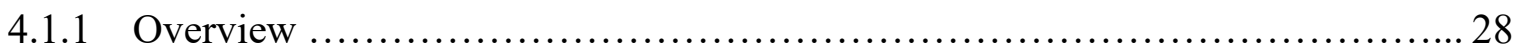

4.1.2 Proposed Universal Control Strategy .................................... 29

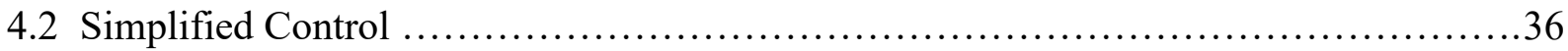

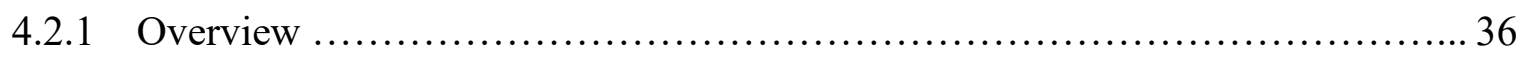

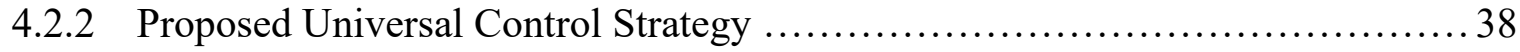

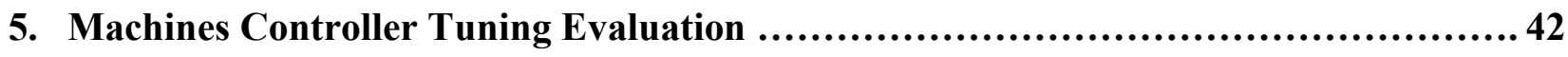

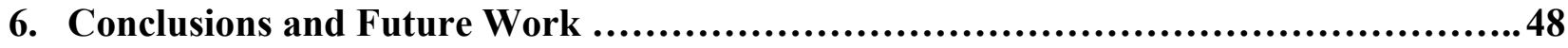

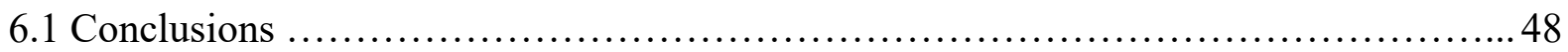

6.2 Future Work ........................................................... 49

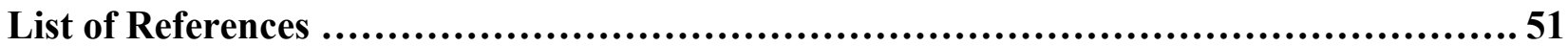




\section{List of Tables}

3.1 Switching vectors, phase voltage and output line-to-line voltage .....................20

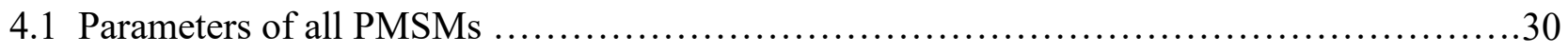

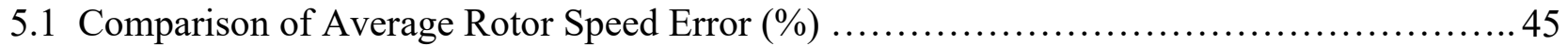

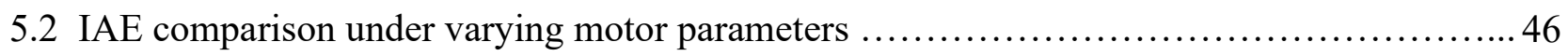




\section{List of Figures}

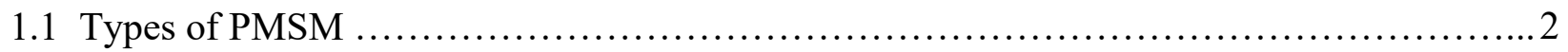

2.1 Classification of control techniques for PMSMs .................................... 6

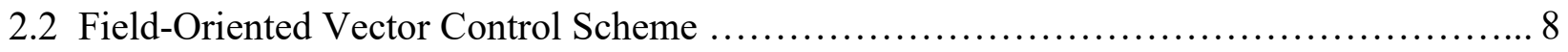

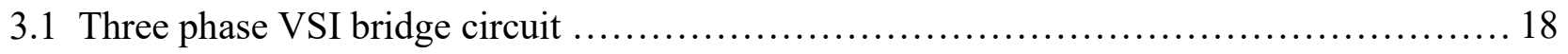

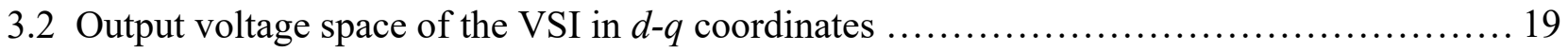

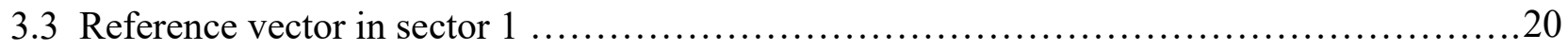

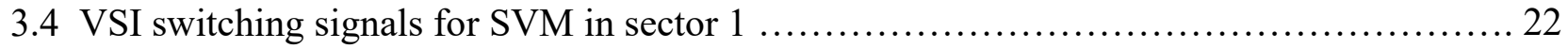

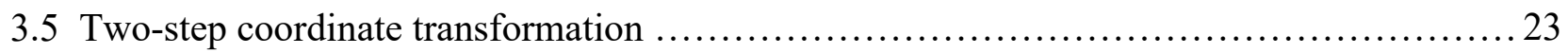

3.6 Combined representation of the coordinate transformations .............................. 24

3.7 Conversion of three phase stationary frame to two phase rotating frame $\ldots \ldots \ldots \ldots \ldots \ldots \ldots \ldots .24$

3.8 Interaction between stator flux and rotor flux in PMSM ................................ 26

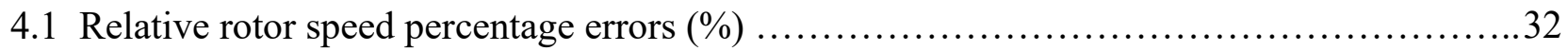

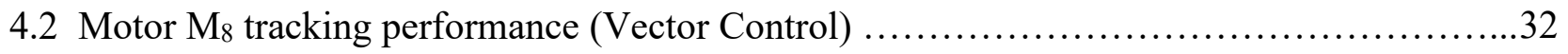

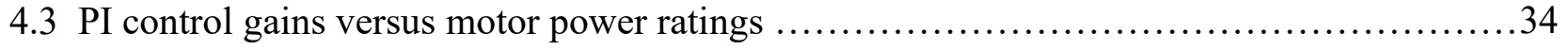

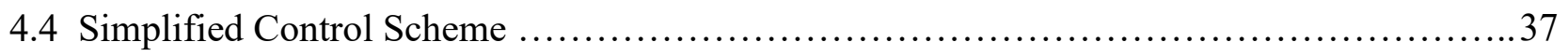

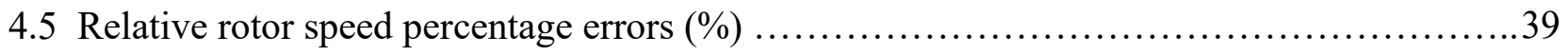

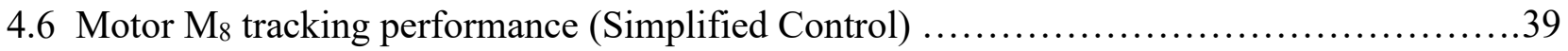

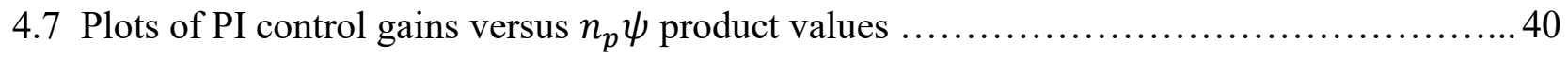

5.1 Errors measured in the vector control method ......................................... 43 
5.2 Errors measured in simplified control method

5.3 Rotor speed errors in percentage (\%) 45

viii 


\title{
List of Abbreviations
}

\author{
Abbreviations Definition \\ PMSM Permanent Magnet Synchronous Motor \\ DC Direct Current \\ $\mathrm{AC}$ \\ Alternating Current \\ EMF Electro-Magnetic Field \\ SPMSM Surface mounted Permanent Magnet Synchronous Motor \\ IPMSM Interior Permanent Magnet Synchronous Motor \\ FOC Field-Oriented Control \\ DTC Direct Torque Control \\ FLC Fuzzy Logic Controller \\ MPC Model Predictive Controller \\ PI Proportional-Integral \\ VSI Voltage Source Inverter \\ STA-SMO Super Twisting Algorithm based Sliding Mode Observer \\ FCS-MPCC Finite Control Set-Model Predictive Current Control \\ PFC Predictive Functional Control \\ ESO Extended State Observer \\ VVC Voltage Vector Control \\ PWM Pulse Width Modulation \\ SVM Space Vector Modulation \\ SM-DTC Sliding Mode-Direct Torque Control
}




$\begin{array}{ll}\text { VSC } & \text { Variable Structure Control } \\ \text { DD } & \text { Direct Drive } \\ \text { SoPC } & \text { System-on-a-Programmable-Chip } \\ \text { ANN } & \text { Artificial Neural Network } \\ \text { AI } & \text { Artificial Intelligence } \\ \text { LM } & \text { Levenberg-Marquardt } \\ \text { DSC } & \text { Dynamic Surface Control } \\ \text { ABSMC } & \text { Adaptive Backstepping Sliding Mode Control } \\ \text { RWFNN } & \text { Recurrent Wavelet Fuzzy Neural Network } \\ \text { RFNCMAN } & \text { Recurrent Fuzzy Neural Cerebellar Model Articulation Network } \\ \text { VSD } & \text { Variable Speed Drives } \\ \text { VVVF } & \text { Variable-Voltage-Variable-Frequency } \\ \text { SVPWM } & \text { Space Vector Pulse Width Modulation } \\ \text { THD } & \text { Total Harmonic Distortion } \\ \text { IAE } & \text { Integral Absolute Error }\end{array}$




\section{List of Symbols}

\begin{tabular}{|c|c|}
\hline Symbols & Definition \\
\hline$\theta$ & rotor angular position \\
\hline$\omega$ & rotor angular velocity \\
\hline$i_{d}$ & $d$-axis current \\
\hline$i_{q}$ & $q$-axis current \\
\hline$v_{d}$ & $d$-axis voltage \\
\hline$v_{q}$ & $q$-axis voltage \\
\hline$L_{d}$ & $d$-axis stator inductance \\
\hline$L_{q}$ & $q$-axis stator inductance \\
\hline$R_{S}$ & stator resistance \\
\hline$J$ & rotor moment of inertia \\
\hline$B$ & viscous friction coefficient \\
\hline$T_{L}$ & load torque \\
\hline$n_{p}$ & number of pole pairs \\
\hline$\psi$ & magnetic flux linkage \\
\hline$i_{d(r e f)}$ & $d$-axis reference current \\
\hline$i_{q(r e f)}$ & $q$-axis reference current \\
\hline$v_{\alpha}$ & $\alpha$-axis voltage \\
\hline$v_{\beta}$ & $\beta$-axis voltage \\
\hline$i_{\alpha}$ & $\alpha$-axis current \\
\hline
\end{tabular}




$\begin{array}{ll}i_{\beta} & \beta \text {-axis current } \\ K_{p \omega} & \text { proportional gain for speed } \\ K_{p d} & \text { proportional gain for } d \text {-axis current } \\ K_{p q} & \text { proportional gain for } q \text {-axis current } \\ K_{i \omega} & \text { integral gain for speed } \\ K_{i d} & \text { integral gain for } d \text {-axis current } \\ K_{i q} & \text { integral gain for } q \text {-axis current } \\ V_{d c} & \text { DC link voltage } \\ V_{r e f} & \text { voltage reference vector } \\ T_{S} & \text { Sampling interval } \\ i_{a} & \text { voltage of phase } b \\ i_{b} & \text { current of phase } a \\ i_{c} & \text { current of phase } b \\ v_{a} & \text { voltage of phase } c \\ v_{c} & \\ & \end{array}$




\section{Chapter 1}

\section{Introduction}

Permanent magnet synchronous motors (PMSMs) are used in various industrial applications due to their many advantages over induction motors like efficiency, torque-to-current ratio and power density. The usage of PMSMs can be seen in a diverse variety of fields such as electric transportation systems, industrial servo drives and renewable energy wind turbines. However, proper optimum control strategies are required to achieve higher continuous torque over a wide range of speeds and better operational efficiency with no magnetizing current. Control techniques ranging from field-oriented vector control to adaptive fuzzy logic control are used to attain better optimum performance. In spite of that, complex control algorithms, higher executing time in real world industrial applications and cost are some of the factors which still need to be addressed.

To overcome such problems, two universal control strategies are proposed in the thesis. The main objective of both these methods is the appropriate control of PMSM even with uncertain system's dynamics. Typical PI controllers are used to control $d-q$ axis currents and speed of the PMSM. These methods use generalized mathematical expressions for automatic gain calculation for PMSMs of a wide power-rating range. This chapter gives some background information on the importance of PMSM characteristics in different applications and the need for sustainable research for simpler control strategies. It also provides an overview on the range of topics discussed in the upcoming chapters. 


\subsection{Background and Motivation}

The structure of PMSM can be considered as a fusion between an induction motor and a brushless DC motor. Its stator structure with windings resembles that of an induction motor, while its permanent magnet rotor is the same as a brushless DC motor. The construction of its stator windings produces a sinusoidal flux density in the air gap of the motor. The PMSM is an AC synchronous motor whose rotor permanent magnets provide the field excitation and has a sinusoidal back EMF waveform. These permanent magnets allow the PMSM to generate torque even at zero speed. Higher torque density with a smaller frame size compared to an AC induction motor is also one of the advantages of the PMSM.

The PMSM can be classified into two types based on the orientation of the permanent magnets attached to the rotor: surface mounted PMSM (SPMSM) and interior PMSM (IPMSM). In SPMSM, the permanent magnets are mounted on the surface of the rotor, while IPMSM has the magnet pieces inside it as shown in Figure 1.1.

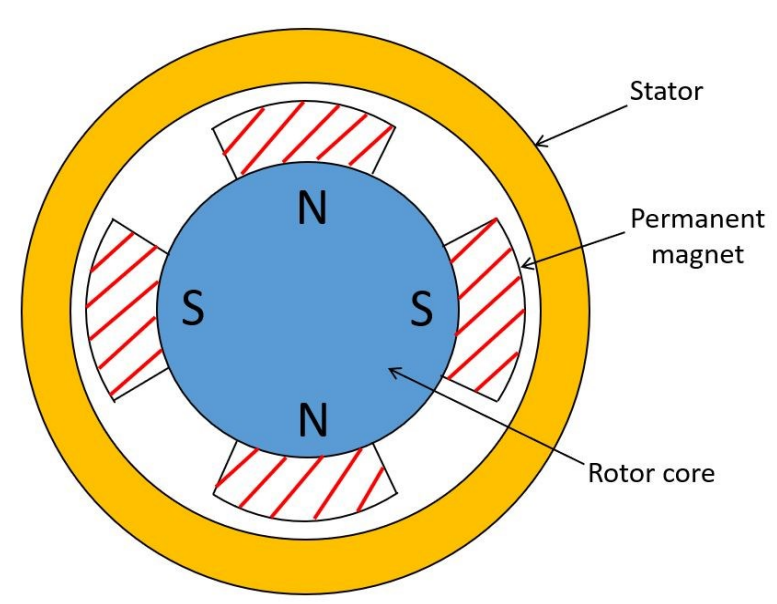

(a)

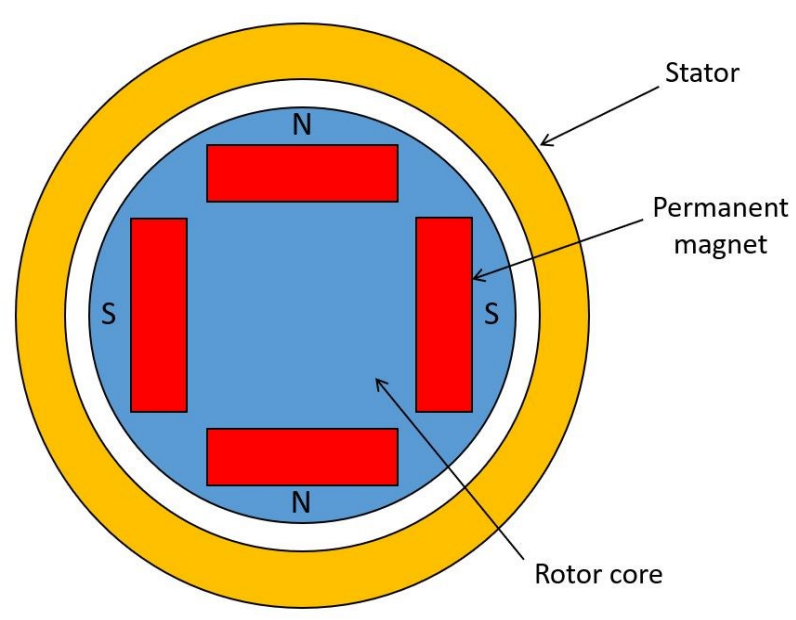

(b)

Figure 1.1: Types of PMSM: (a) SPMSM, (b) IPMSM 
Usually, a digitally controlled inverter is used for the PMSM operations where it can also generate torque at zero speed. Several control techniques are used for the smooth rotation of the PMSM over an entire speed range giving high performance output. The most common and widely used control methods are the vector control techniques which are mainly classified into two categories: field-oriented control (FOC) and direct torque control (DTC) [1]. The FOC method is used by various types of controllers like PI-Controller, Sliding Mode Controller (SMC), Fuzzy Logic Controller (FLC) and Model Predictive Controller (MPC) [2-5]. The main objective is to break down the stator current into magnetic field generating component and torque generating component and control both these parts separately [6]. Mathematical transformations are used by the FOC method to obtain the torque and flux of a PMSM from a three-phase current feedback. More detailed description about this control technique is mentioned in Chapter 4. Unlike FOC, the DTC method doesn't require any complex coordinate transformation and current regulator but it has some drawbacks such as poor control at low speed and torque ripples [7]. Fuzzy logic and neural network are some of the emerging non-linear control techniques which have gained interest in recent years in the domain of PMSM control. Most of the conventional control methods have the disadvantages of large speed fluctuations at constant load, more computational complexity and operational expenditure. However, despite of the many theoretical advances achieved in the domain of PMSM control, more research is needed in the field of intelligent learning-based control techniques and better experimental validation is also required for the most favorable control methods. 


\subsection{Objectives and Contributions}

The goal of this thesis is to overcome the above mentioned drawbacks and system complexities by establishing a simpler approach for better PMSM control even with uncertain system's dynamics. Here, two of such control methods are proposed: conventional field-oriented vector control and simplified control. These two methods reduce the operational time required for PMSM tuning using an automatic gain calculating algorithm with the help of some generalized mathematical expressions. Besides, compared to the aforementioned control methods, the techniques formulated here can be applied to multi-power range motor types.

In vector control, the control gains are determined using only the motor power ratings. Accurate tracking of $d-q$ axis currents and speed of the PMSM is observed with the help of a self-tuned PI controller. Afterwards, to validate this proposed tuning method, some new PMSMs are simulated using these generalized mathematical expressions and the results show accurate tracking of the currents and speed. The simplified control scheme makes the use of the influence of PMSM modeling equations on the $d-q$ axis currents and speed control tracking. Here, much simpler mathematical expressions are obtained compared to the vector control for each of the PI controller gains. For the automatic gain calculation, it considers the product of the no. of pole pairs and flux linkage. Both these proposed tuning methods don't use complex control algorithms and are much simpler and convenient to apply. This approach also requires very minimal information of the motor's dynamics. All the simulations are carried out in the MATLAB/Simulink environment and responding conclusions are made. 


\subsection{Organization of the Thesis}

The rest of the thesis is organized as follows. Chapter 2 briefly presents the various control methods available for the PMSM control and tuning. All the conventional techniques in the domain of vector control are discussed and some new emerging control methods using fuzzy logic and neural network approach are outlined in the end. Following this, the modeling of PMSM involving its structure and working is discussed in Chapter 3. Chapter 4 reviews the proposed universal control strategy and its formulation in detail. It provides an approach to the two control methods of field-oriented vector control and simplified control. Next, Chapter 5 presents all the simulation results obtained in the MATLAB/Simulink software and analyses all the errors in $d-q$ axis currents and speed. Finally, Chapter 6 provides the concluding remarks and future research opportunities. 


\section{Chapter 2}

\section{Literature Review}

This chapter reviews the various existing and emerging control techniques of PMSMs and their classifications in detail. The methods are listed in Figure 2.1 and are classified by their basic qualitative characteristics.

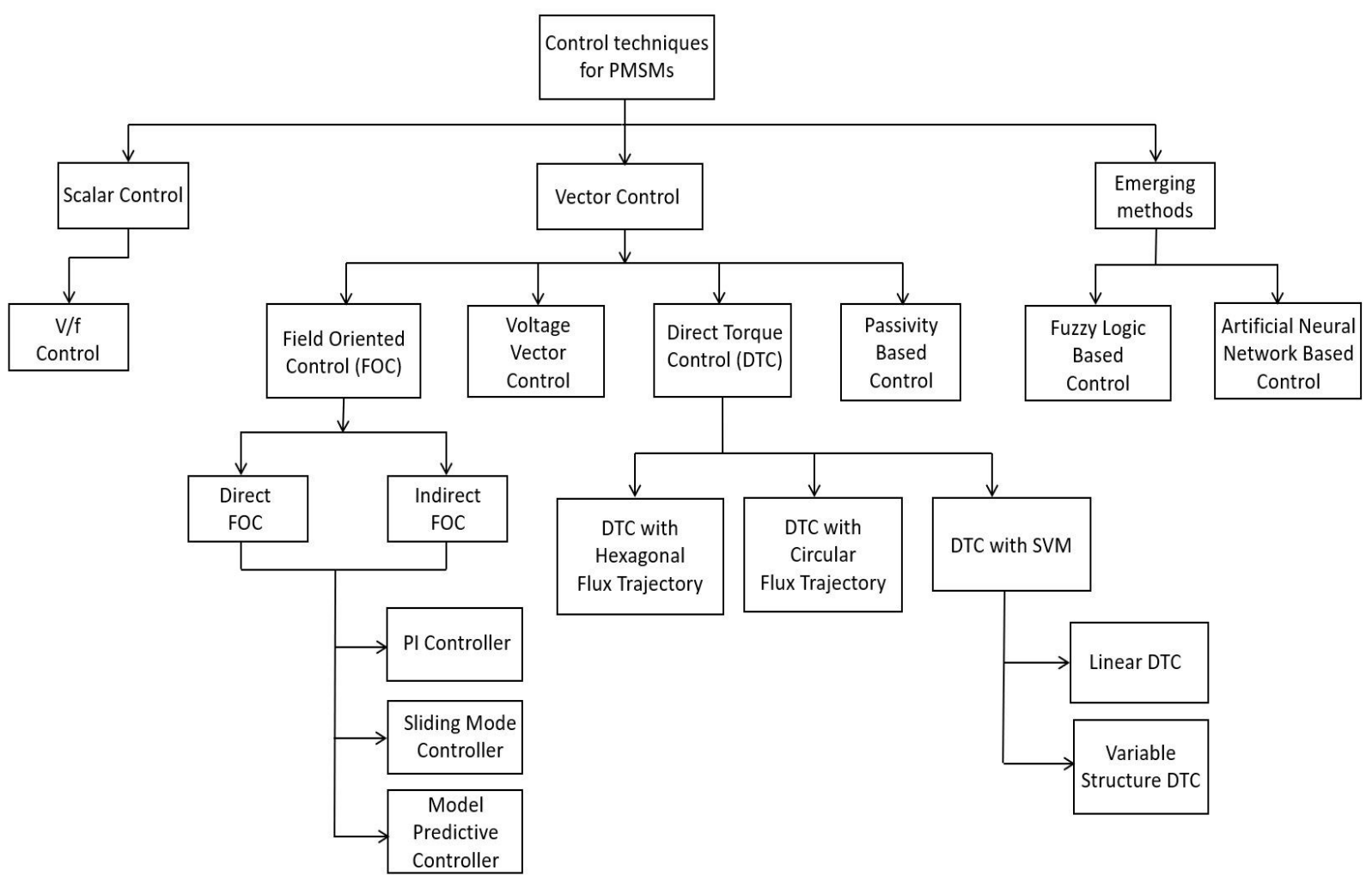

Figure 2.1: Classification of control techniques for PMSMs 


\subsection{Scalar Control Method}

Scalar V/f (Voltage/frequency) control is one of the simplest methods for PMSM control where the relationship between voltage or current and frequency is kept constant according to the motor's speed range. The motor's parameters or position are not used here as a feedback, as this technique uses open loop control [8]. This results in consuming less computation power for the hardware control and the drive system becomes unstable after exceeding a certain applied frequency. For this, damper windings are constructed in the rotor of PMSM to achieve synchronization with the frequency. In [8], an open-loop V/f stabilization technique is presented for a five-phase PMSM which maintains the stability of the drive system over a wide range of speed. Two feedback corrections are used in [9] for the V/f control as: (i) use of active power variation for speed stabilizing correction to maintain the stator applied frequency for stable operation, and (ii) applying PI regulation of $q$-axis current component for voltage amplitude correction to achieve unity power factor.

\subsection{Vector Control Methods}

This section discusses the four main control methods using the vector control approach and their classifications.

\subsubsection{Field Oriented Control (FOC)}

FOC is much widely accepted as one of the vector control methods. Direct FOC can be described as shown in Figure 2.2 with a rotor position sensor. 


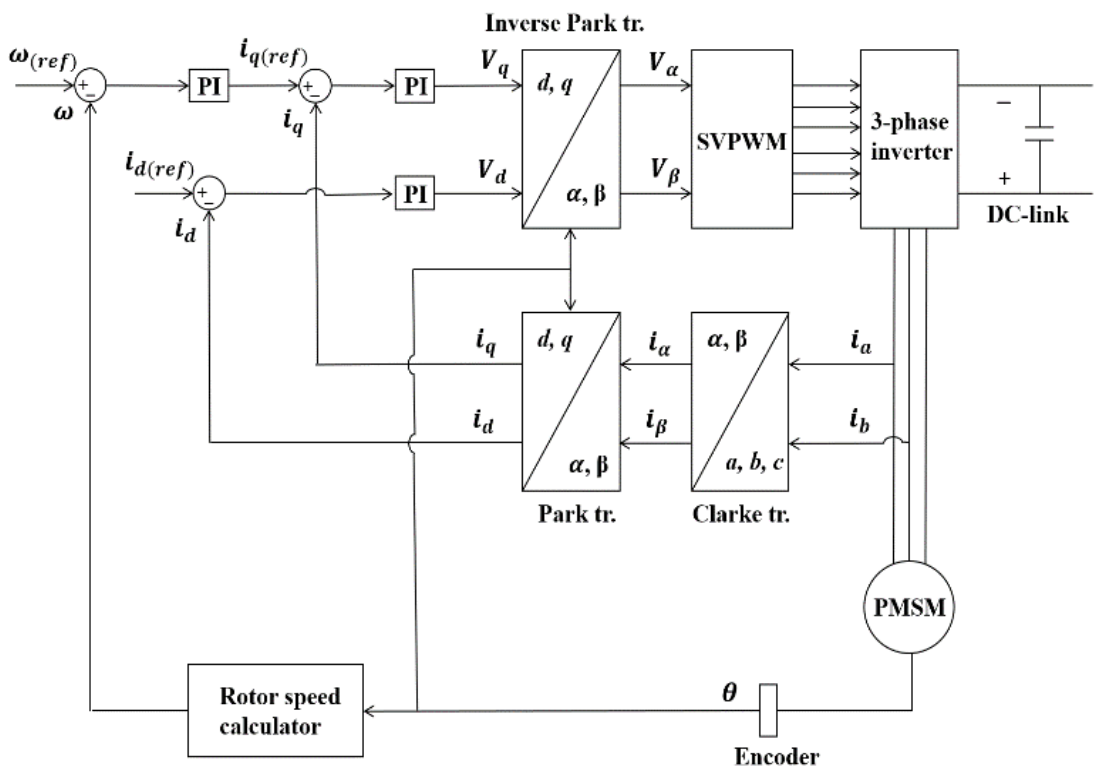

Figure 2.2: Field-Oriented Vector Control Scheme

Here, the stator phase currents are measured and transformed to two phase $\alpha \beta$ system using Clarke transformation [2]. Afterwards, these currents are converted to rotating $d$ - $q$ reference frame via Park transformation [2]. The calculated rotor position using the position sensor is used to compare the actual and reference speeds to generate $q$-axis reference current [10]. The outputs of the two PI controllers, $i_{d(r e f)}$ and $i_{q(\text { ref })}$ are obtained from the feedback signals and are used for the motor flux and torque control respectively [2]. This is the main principle of FOC. The FOC circuit without any position sensor is also known as Indirect FOC method.

The $d-q$ axis current control has a vital role to play in a vector controlled PMSM to achieve better system's dynamic performance [11]. Current control is also important as it has a direct effect on torque control [12]. The use of Proportional-Integral (PI) controllers is the most common approach in the implementation of $d-q$ axis currents and speed control loops due to their simplicity [11]. Several tuning methods for obtaining the PI control gains have been proposed in recent years 
[13]. Trial-and-error and Ziegler-Nichols are some of the most commonly used tuning methods for controlling PMSM [13]. But the accuracy of these methods depends on the full knowledge of the PMSM model parameters [13]. It is difficult to obtain good performance using linear control algorithms, as the PMSM is a nonlinear system with strong coupling that is subject to parameter variations [11]. Many nonlinear control methods have come to light due to the recent developments in motor control techniques [11]. In [14], a boundary layer integral sliding mode controller is designed based on a quasi-linearized and decoupled model considering the effect of parameter variations. In [15], the non-linearity of a voltage source inverter (VSI) is considered to propose an adaptive super-twisting algorithm based sliding mode observer (STA-SMO) for the surface mounted PMSMs. To achieve better accuracy of the PMSM model, the voltage distortion due to VSI non-linearity is compensated online [15]. A simple adaptive disturbance observer is used in [16] with a robust controller, which uses an adaptive element in the reference-voltage-generation stage using the feedforward control. Depending on the various operating conditions of the PMSM, the adaptive element is selected as an uncertainty function which changes accordingly [16]. In the last few years, better control techniques incorporating predictive current controllers [17-19] are receiving attention in PMSM drives' domain. A discrete-time robust predictive current controller is proposed in [17], based on the dead-beat structure. But unmodeled dynamics and parametric uncertainties act as some of the drawbacks of the dead-beat control [17]. In [18], the current control is achieved while satisfying the real-time and physical constraints of PMSM drives by obtaining fast transient current response adjusting the stator voltages. A five-phase PMSM is controlled using the proposed finite control set model predictive current control (FCS-MPCC) in [19]. At low speed, the sensor-less control of PMSM can be accomplished by a signal injection method in [10], which ideally requires only one voltage vector for position estimation. In [20], a control Lyapunov 
function over a discrete set of realizable inputs generates the input switching sequences for the PMSM control system. Each input has its own stabilizing effect on the control system [20], upon which the switching decisions can be made for the input selection process. In [21], a predictive functional control (PFC) technique is proposed for the control design of the speed loop. But the PFC method does not give proper results in the case of strong disturbances, due to which an extended state observer (ESO) is introduced, which adds a feedforward compensation item based on the estimated disturbances [21]. In [22], the control of a PMSM driven by a matrix converter is accomplished using a new speed finite control set model predictive control algorithm that uses a single control law instead of the cascaded control scheme.

Unlike various control methods reported in the literature, this thesis presents the concept of autotuning using a classical PI control approach due to its design simplicity and good performance. The auto-tuning technique has been applied to various other applications like control of quadcopter, temperature control in furnace and reinforcement learning neural networks. In [23], an altitude control algorithm is presented for a quadcopter using the advantage of conventional proportional-integral-derivative (PID) control technique by resolving some of its drawbacks. In [24], the stability of an autonomous quad-rotor is achieved using the PID control strategy. An autonomous quadcopter robust landing algorithm is proposed in [25] to accomplish precision landing task. In [26], temperature control of a diffusion furnace is achieved using PID controller tuned with the help of a frequency loop-shaping method. PID controller is used for stabilization of modern voltage regulator system in [27], which can help the technicians and engineers in better understanding of digital controller tuning. Thus, several control methods are available but the PID control approach is widely used in a variety of applications across the world [23]. In [28], an efficient PID controller gain auto-tuning method is proposed through reinforcement learning 
neural networks for a complex system like a multicopter. The neural network is trained and gets updated every time till it chooses the best action to find the controller gains [28]. Various autotuning techniques are also presented in [29-31] which need little prior system information and are robust to noise. Although the aforementioned control methods achieve good performance, but they use very complex control algorithms which increases the computational burden. The proposed method to find the PI controller gains uses simple mathematical expressions which make it more suitable for low-cost real-time implementation. Besides, compared to the aforementioned control methods, the proposed technique can be applied to multi-power range motor types.

\subsubsection{Voltage Vector Control (VVC)}

In this method, reference frame transformations are used but without the need for the rotor position information [2]. The circuit structure and computational algorithms of VVC are less complicated compared to the FOC [2]. In this control strategy, only the flux component of stator current is taken into account [2]. Higher torque overshoot and ripple problems are some of the disadvantages of VVC compared to FOC [2]. In [32], a position estimation method is proposed to overcome the above mentioned drawbacks using derivative calculations of current and zero voltage vector injection. [10] discusses a control strategy where only one voltage vector is required for position estimation to execute sensor-less control of PMSM.

\subsubsection{Direct Torque Control (DTC)}

In 1988, M. Depenbrock suggested an alternative method to FOC called as Direct Torque Control (DTC) approach [33]. This control strategy does not require speed sensor and an inverter with PWM which makes its circuit less complex compared to the FOC. PMSM drives using this control 
method have robust nature against any changes in the motor parameters and also respond quickly to any load variations [2]. M. Depenbrock developed the DTC technique with hexagonal flux trajectory, whereas I. Takahashi and T. Noguchi suggested the control approach with circular flux trajectory [2]. To overcome the drawbacks of conventional DTC, a modified approach using DTC with Space Vector Modulation (SVM) is used. This method improves the efficiency of PMSM drive and also reduces flux and torque ripples [2]. It uses the pulse width modulation (PWM) technique to generate the voltage in control system. In Linear DTC method, the non-linear system is represented as a linear one using Feedback Linearization approach [2]. Sliding Mode DTC (SM DTC) uses sliding mode controllers, while Linear DTC uses PI controllers to maintain torque and flux [2]. In [34], the reduction of torque ripple and stator flux ripple is achieved using the proposed duty ratio modulated direct torque control technique. In [35], the torque and flux ripple reduction can be observed while improving the dynamic response of the classical DTC technique with the help of a new predictive DTC strategy. In [36], the internal model principle and variable structure control (VSC) approach is combined to obtain a new hybrid control model, and a direct instantaneous torque control scheme is proposed for a direct drive (DD) PMSM.

\subsection{Emerging Methods}

In recent years, artificial intelligence techniques such as fuzzy logic and artificial neural networks are gaining more attention in the field of PMSM control thanks to their many advantages over the conventional methods. 


\subsubsection{Fuzzy Logic Based Control}

The concept of fuzzy logic was first introduced in the 1960s by Dr. Lotfi Zadeh of the University of California at Berkeley. Modern computer systems are based on the Boolean logic values of 1 and 0 , while the fuzzy logic also considers various truth states which can't be represented as completely true or false. Fuzzy logic can also handle non-linearity with vague inputs without the need of any precise mathematical model. Fuzzy Logic Control (FLC) methods disintegrate the complex systems into smaller subsystems according to human knowledge about that system [37]. Considering the human control strategy, many local and straightforward control laws are established [37]. Combining all these local control actions, a global control law is built through fuzzy membership functions [37]. Instead of using a complicated mathematical model, FLC uses 'IF-THEN' conditional statements according to human mind's consideration of linguistic variables with smaller and simpler techniques [37].

Fuzzy Logic Controller (FLC) mainly includes three stages: fuzzification, inference and defuzzification [37]. In the first phase called fuzzification, triangular membership functions are used to convert crisp variables into fuzzy variables [38]. Considering the fuzzy rules in the rule base, the output membership functions are processed [39]. Each universe of discourse is divided into seven fuzzy sets: NL (Negative Large), NM (Negative Medium), NS (Negative Small), Z (Nearly Zero), PS (Positive Small), PM (Positive Medium), PL (Positive Large) [38]. Each fuzzy variable is a member of the subsets with a degree of membership which changes between 0 (nonmember) and 1 (full-member) [39]. In the second stage called inference, a fuzzy relation matrix is created which gives a relationship between fuzzy set characterizing controller inputs and fuzzy set characterizing controller outputs [38]. An inference engine performs a set of control rules contained in a $7 \times 7$ rule base which processes the fuzzy variables [38]. The behavior knowledge 
of PMSM is used to establish the control rules [38]. In the third phase called defuzzification, the inference output variable is converted into crisp value using one of the many available defuzzification algorithms [38].

A fuzzy PI-type current controller is used in [40], which stabilizes the decoupled dynamics and ensures the stability of the PMSM. But this approach has some problems dealing with the timevarying uncertainties [40]. In [41], a speed control integrated circuit (IC) is proposed under a system-on-a-programmable-chip (SoPC) environment for the PMSM drive. Here, the external load effect and dynamic uncertainty in the speed loop of a PMSM is considered for the operation of an adaptive fuzzy controller [41]. A decentralized adaptive fuzzy controller for the PMSM drive is used in [42], based on the type-2 fuzzy logic systems and adaptive control theory.

\subsubsection{Artificial Neural Network Based Control}

A neuron is the basic structural unit of Artificial Neural Network (ANN), which is derived from the concept of a biological neuron [43]. A biological neuron comprises of many branches classified as dendrites and axon [43]. The dendrites receive the impulse signals and when a certain threshold limit is reached, an appropriate response signal is generated as on output [43]. This response signal is transferred to other neurons through a complex branching system with the help of axon [43]. The incoming signals (inputs) are weighted and summed after reaching the neuron body, and then converted into outgoing signals after passing through the transfer function [43]. ANN is made up of three layers: input layer, hidden layer/s and output layer [44]. The input layer receives data from the network and passes it to the hidden layer/s in the form of raw information [44]. The hidden layer/s processes this data and transfers it to the output layer [44]. There can be two types of neural networks depending on the interconnection of different nodes between layers namely feedforward 
neural network and recurrent neural network [44]. Information moves from inputs to outputs in only one direction in the feedforward ANN, while in the recurrent ANN, some of the information moves in the opposite direction [44].

Neural Network Controller can be used in place of the conventional PI based current controller to solve the issue of decoupling inaccuracy. The $d-q$ axis current control has a vital role to play in a vector controlled PMSM to achieve better system's dynamic performance [11]. Current control is also important as it has a direct effect on torque control [12]. The various design stages of the $\mathrm{NN}$ controller correspond to the design levels of the conventional controller and needs to be specified [12]. Similar to the tuning of the conventional controller, the NN controller requires to be trained [12]. The development time of a system consisting of NN controller reduces as the Artificial Intelligence (AI) based system requires less effort than a conventional PI controller [45]. The number of nodes in the hidden layer of the NN structure is obtained through trial-and-error approach. The signals are fed to the nodes of hidden layer from the input layer and after getting processed through hyperbolic tangent activation functions, the output layer generates the output. During the NN training, its weights are adjusted to achieve suitable optimal control of the PMSM [12]. The weights represent the strength of the connection between two nodes [45]. Usually, NN network is trained using the Levenberg-Marquardt (LM) optimization method as it is the most used method to train feedforward networks with less computing time [12].

An artificial neural network (ANN) based real-time adaptive controller is proposed in [46], which initially generates estimated coefficients using an offline training method. Then, to update the ANN, an online training is executed using the dynamic back-propagation with the LevenburgMarquardt algorithm [46]. In [47], the unknown and nonlinear functions of the PMSM are approximated using neural-networks (NNs) and an adaptive dynamic surface control (DSC) is 
proposed. A speed control strategy for a six-phase PMSM is proposed in [48] using a robust adaptive backstepping sliding mode control (ABSMC) with recurrent wavelet fuzzy neural network (RWFNN) considering the load disturbances and parameter variations. In [49, 50], a recurrent fuzzy neural cerebellar model articulation network (RFNCMAN) is considered for a sixphase PMSM position servo drive system, which is also equipped with a fault tolerant control scheme. 


\section{Chapter 3}

\section{Modeling of PMSM}

PMSM has become widely known for its different control applications compared to other motor types. For instance, it is used greatly in the industrial sector, actuators, robotics and vehicle propulsion systems. Numerous advantages like high power density, high efficiency and low torque ripple make the PMSM favorable for several commercial and residential applications. PMSM is called a synchronous machine as the stator electrical frequency is directly proportional to the rotor speed in steady state.

The PMSM can be described in the form of the following nonlinear mathematical equations in the $d-q$ reference frame [47]:

$$
\begin{gathered}
\frac{d \theta}{d t}=\omega \\
J \frac{d \omega}{d t}=\frac{3}{2} n_{p}\left[\left(L_{d}-L_{q}\right) i_{d} i_{q}+\psi i_{q}\right]-B \omega-T_{L} \\
L_{d} \frac{d i_{d}}{d t}=-R_{S} i_{d}+n_{p} \omega L_{q} i_{q}+v_{d} \\
L_{q} \frac{d i_{q}}{d t}=-R_{s} i_{q}-n_{p} \omega L_{d} i_{d}-n_{p} \omega \psi+v_{q}
\end{gathered}
$$

where $\theta$ is the rotor position, $\omega$ is the rotor angular velocity, $i_{d}$ and $i_{q}$ denote the $d-q$ axis currents, $v_{d}$ and $v_{q}$ stand for the $d-q$ axis voltages, $L_{d}$ and $L_{q}$ are the $d-q$ axis stator inductances, $R_{s}$ denotes 
the stator resistance, $J$ stands for the rotor moment of inertia, $B$ denotes the viscous friction coefficient, $T_{L}$ is the load torque, $n_{p}$ is the number of pole pairs, $\psi$ represents the magnetic flux linkage. Here, $L_{d} \neq L_{q}$ for interior permanent magnet synchronous motor and $L_{d}=L_{q}$ for surface-mounted permanent magnet synchronous motor.

\subsection{Inverter block}

Voltage Source Inverters (VSIs) are used in a wide variety of applications like frequency converters, variable speed drives (VSDs) and active filters using various PWM techniques. VSI provides an output of AC voltage and frequency from a constant DC voltage source. Figure 3.1 mentions a simple two-level inverter circuit consisting of six power semiconductor switches with antiparallel diodes. $\mathrm{S}_{1}-\mathrm{S}_{6}$ are six semiconductor switches which can be controlled by giving appropriate gate signals and the circuit produces a variable-voltage-variable-frequency (VVVF) output [51]. Switches $\mathrm{S}_{1}-\mathrm{S}_{4}, \mathrm{~S}_{3}-\mathrm{S}_{6}$ and $\mathrm{S}_{5}-\mathrm{S}_{2}$ are switched in a complementary manner.

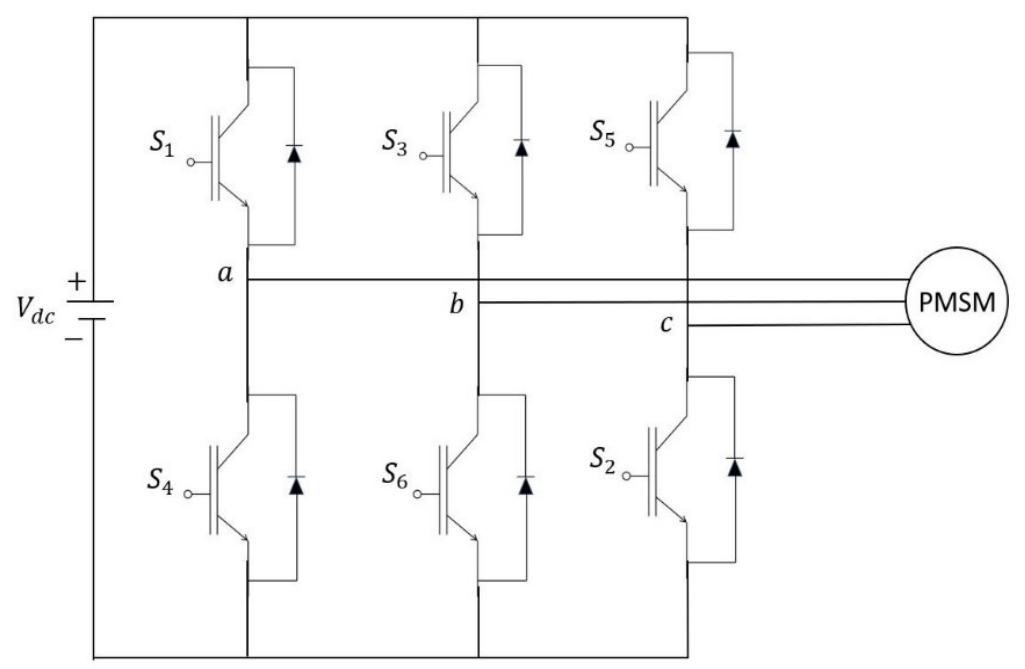

Figure 3.1: Three phase VSI bridge circuit 
Space Vector Modulation (SVM) is one of the most used PWM techniques due to its wide linear modulation range and simple digital implementation [51]. Space Vector Pulse Width Modulation (SVPWM) can be executed by identifying sector using coordinate transformation and determining switching vectors in best switching sequence [51]. There are total eight possible switching vectors in which six produce a non-zero voltage and the remaining two produce a zero-voltage output [51].

The eight different combinations of switching states are: 000, 100, 110, 010, 011, 001, 101 and 111. As shown in Figure 3.2, the space vector plane is divided into six equal sectors of $60^{\circ}$ with equal magnitude by the six active vectors, while the two zero space vectors are found at the origin [51]. The six active voltage space vectors have an equal magnitude of $(2 / 3) V_{d c}$ for a given DC link voltage [52]. All the possible switching vectors and their respective line to line/line to neutral voltages are mentioned in Table 3.1. A voltage reference vector is generated in terms of a revolving space vector to get a sinusoidal waveform from the VSI [51].

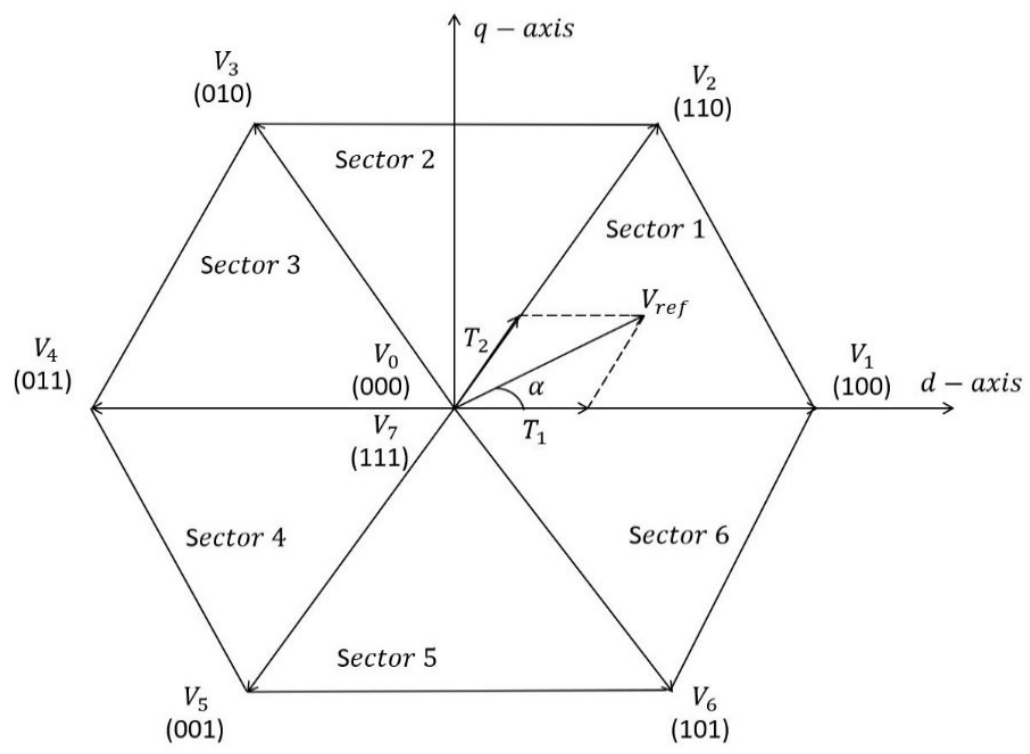

Figure 3.2: Output voltage space of the VSI in $d-q$ coordinates 
Table 3.1: Switching vectors, phase voltage and output line-to-line voltage

\begin{tabular}{cccccccccc}
\hline $\begin{array}{c}\text { Voltage } \\
\text { vectors }\end{array}$ & \multicolumn{2}{c}{ Switching vectors } & \multicolumn{3}{c}{ Pole voltage } & \multicolumn{3}{c}{ Line voltage } \\
\hline & $a$ & $b$ & $c$ & $V_{a 0}$ & $V_{b 0}$ & $V_{c 0}$ & $V_{a b}$ & $V_{b c}$ & $V_{c a}$ \\
$V_{0}$ & 0 & 0 & 0 & 0 & 0 & 0 & 0 & 0 & 0 \\
$V_{1}$ & 1 & 0 & 0 & $2 / 3$ & $-1 / 3$ & $-1 / 3$ & 1 & 0 & -1 \\
$V_{2}$ & 1 & 1 & 0 & $1 / 3$ & $1 / 3$ & $-2 / 3$ & 1 & 0 & -1 \\
$V_{3}$ & 0 & 1 & 0 & $-1 / 3$ & $2 / 3$ & $-1 / 3$ & -1 & 1 & 0 \\
$V_{4}$ & 0 & 1 & 1 & $-2 / 3$ & $1 / 3$ & $1 / 3$ & -1 & 0 & 1 \\
$V_{5}$ & 0 & 0 & 1 & $-1 / 3$ & $-1 / 3$ & $2 / 3$ & 0 & -1 & 1 \\
$V_{6}$ & 1 & 0 & 1 & $1 / 3$ & $-2 / 3$ & $1 / 3$ & 1 & -1 & 0 \\
$V_{7}$ & 1 & 1 & 1 & 0 & 0 & 0 & 0 & 0 & 0 \\
\hline
\end{tabular}

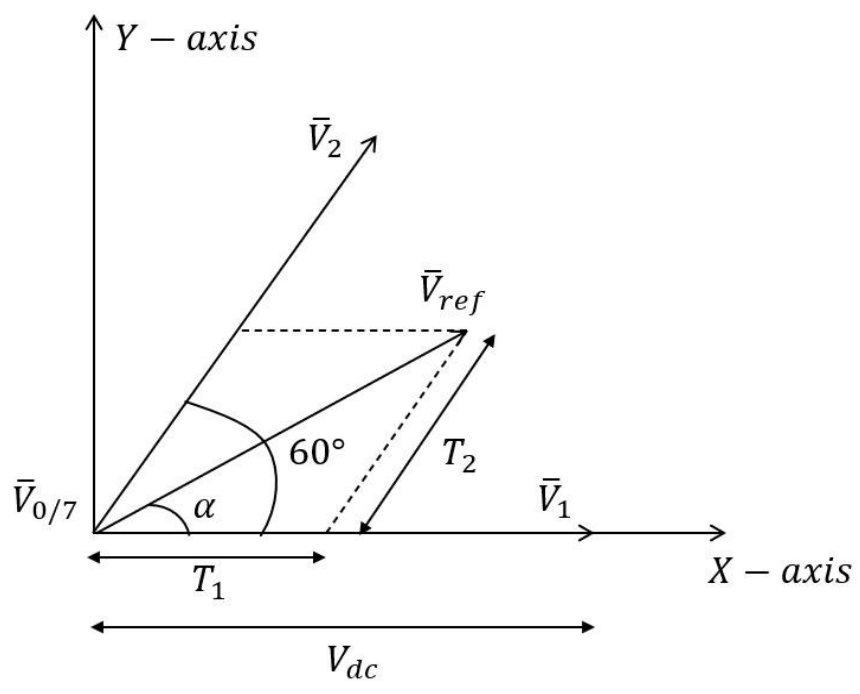

Figure 3.3: Reference vector in sector 1 
For every sub-cycle, the reference vector is sampled once [51]. The SVM method has four switching rules: (a) only one switching by state transition, (b) in one sampling period, there should be no more than three switching, (c) $V_{r e f}$ should be in a circular trajectory, (d) the initial state of next sample must be the final state of previous sample [51]. These rules help in the switching loss decrement and also lower Total Harmonic Distortion (THD) by maintaining symmetry in switching waveforms [51].

As shown in Figure 3.3, the switching states 0,1,2 and 7 can be used in Sector 1. Reference voltage $\bar{V}_{r e f}$ can be expressed as follows while using SVPWM [51]:

$$
\bar{V}_{r e f}=\left(\frac{T_{1}}{T_{S}} \times \bar{V}_{1}\right)+\left(\frac{T_{2}}{T_{S}} \times \bar{V}_{2}\right)+\left(\frac{T_{0}}{T_{S}} \times \bar{V}_{\frac{0}{7}}\right)
$$

where $T_{S}$ is the sampling interval.

The inverter remains in active state 1 for time interval $T_{1}$, in active state 2 for period $T_{2}$ and there is no voltage in inactive states 0 or 7 . The time intervals $T_{1}$ and $T_{2}$ can be calculated as follows [51]:

$$
\begin{gathered}
T_{1}=\bar{V}_{r e f} \sin \left(60^{\circ}-\alpha\right) \\
T_{2}=\frac{\bar{V}_{r e f} \sin (\alpha)}{\sin \left(60^{\circ}\right)} \\
T_{Z}=T_{S}-T_{1}-T_{2}
\end{gathered}
$$

where $\alpha$ is the angle of rotating vector $\bar{V}_{r e f}$.

Time interval $T_{Z}$ is divided between two zero state vector components $\bar{V}_{0}$ and $\bar{V}_{7}$.

For a particular modulation cycle, the active and zero state time intervals are computed which generate switching signals $\mathrm{PWM}_{1}, \mathrm{PWM}_{2}$ and $\mathrm{PWM}_{3}$ as mentioned in Figure 3.4 where $m$ represents the sector number [52]. 


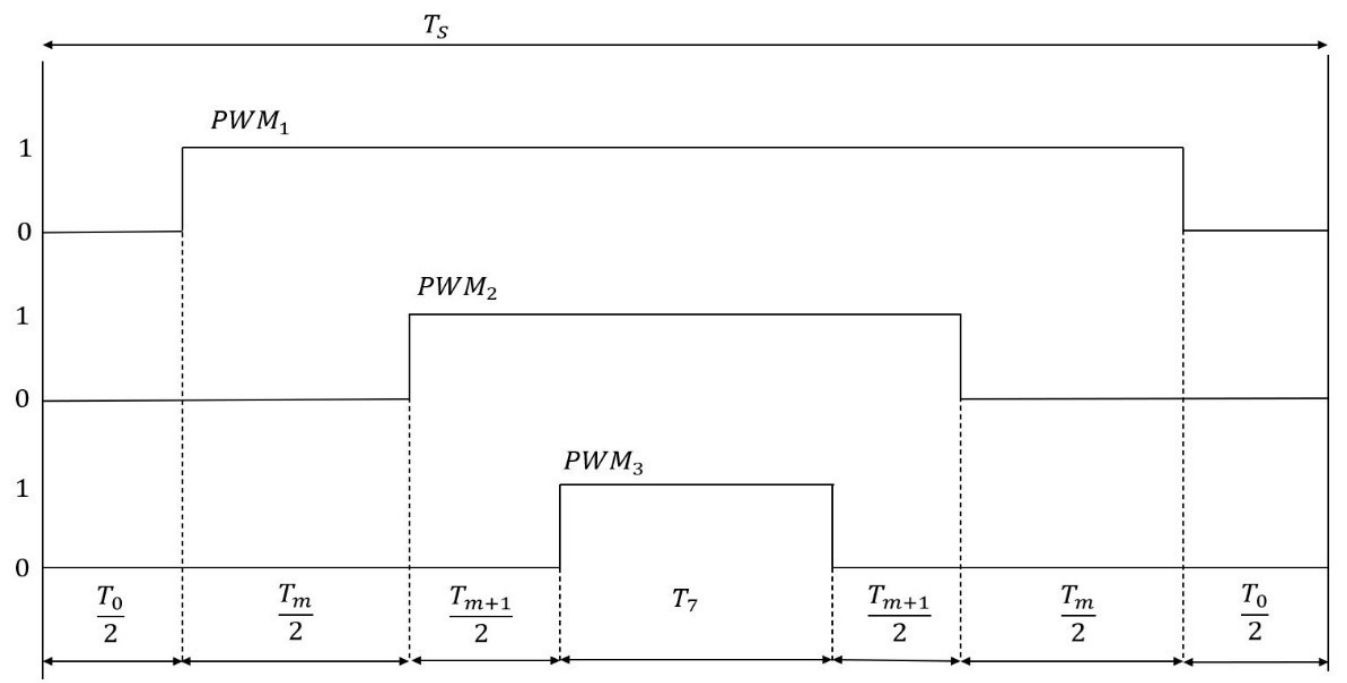

Figure 3.4: VSI switching signals for SVM in sector 1

\subsection{Control block}

Currents producing the flux and torque components in DC motors are orthogonal and can be controlled independently. The armature current can control the torque if the flux is kept constant due to which the DC machines are said to have independent flux and torque control. But in AC machines, the stator and rotor fields are not perpendicular to each other. Stator phase currents from stationary reference frame are transformed to torque and flux producing currents in rotating reference frame to achieve decoupled control using Field Oriented Control (FOC).

The FOC method uses three reference frames and requires transformations from one frame to another mentioned as follows [53]:

1. Stator reference frame where $a, b, c$ are co-planar and at $120^{\circ}$ to each other. 
2. An orthogonal reference frame $(\alpha \beta)$ in which the angle between two axes is $90^{\circ}$ instead of $120^{\circ}$ but in the same stator reference frame.

3. Rotor reference frame $(d q)$ in which $d$-axis is aligned with the flux vector or North and South poles of rotor, while $q$-axis is at $90^{\circ}$ with the $d$-axis.

These transformations used for decoupling the stator currents into flux $\left(i_{d}\right)$ and torque $\left(i_{q}\right)$ generating components are given in Figure 3.5. All these quantities are combined and represented in the following Figure 3.6.

To control the flux and torque producing components independently, the stator currents in three phase stator reference frame are transformed to two axis rotating $d q$ rotor reference frame in two steps as mentioned in Figure 3.7 [53].
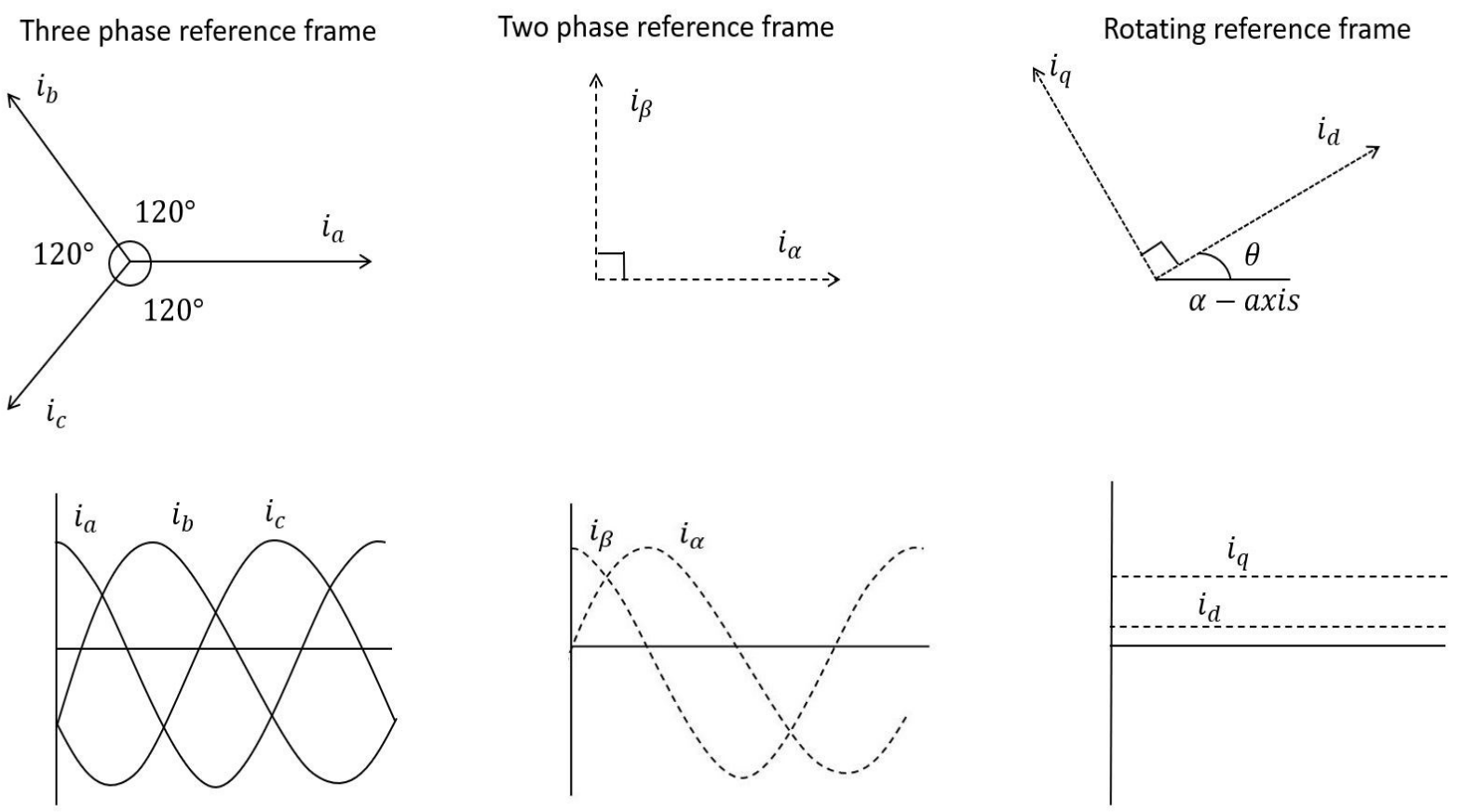

Figure 3.5: Two-step coordinate transformation 


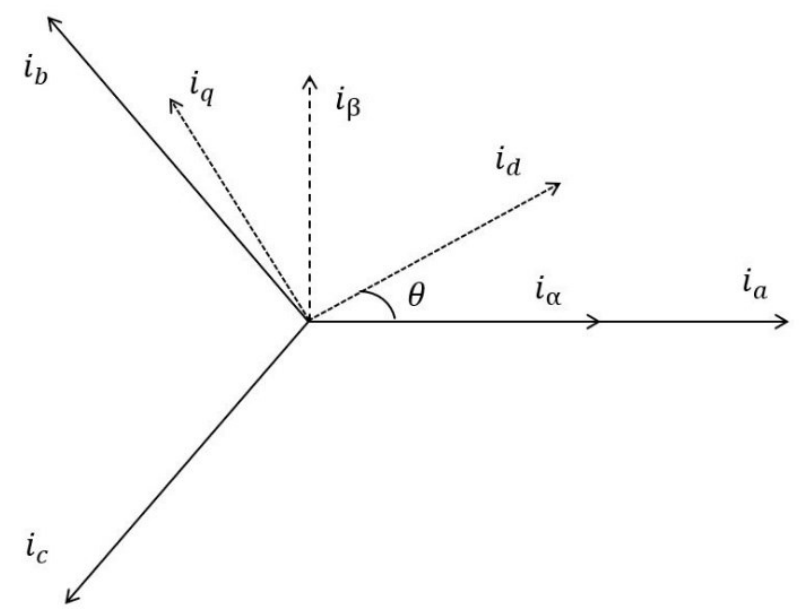

Figure 3.6: Combined representation of the coordinate transformations

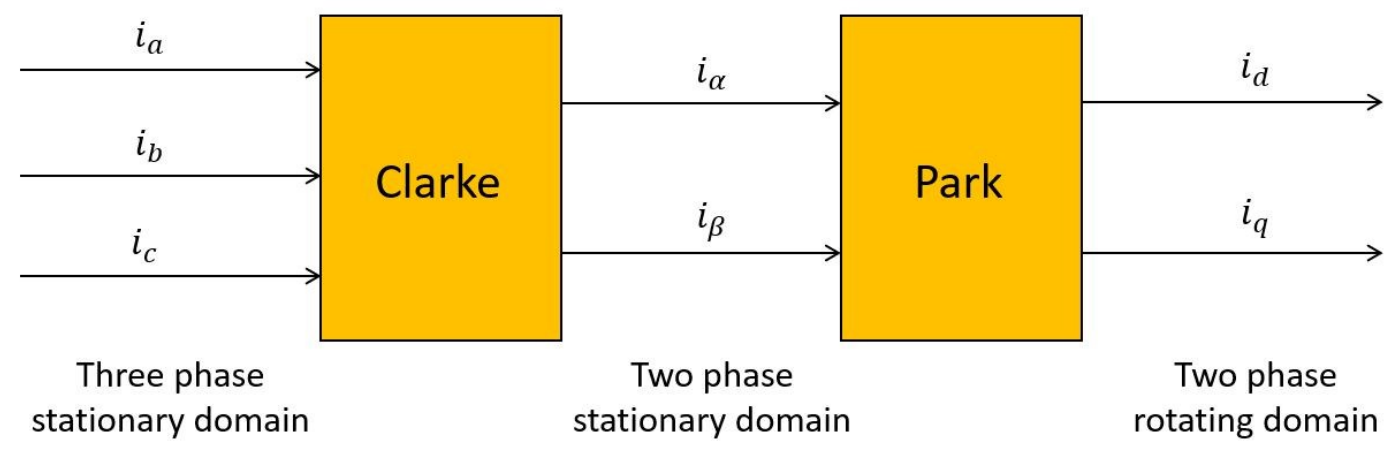

Figure 3.7: Conversion of three phase stationary frame to two phase rotating frame

\section{Clarke Transformation:}

The motor currents are measured and transformed from three phase reference frame to two axis orthogonal reference frame using the following equations [54]. 


$$
\left[\begin{array}{l}
i_{\alpha} \\
i_{\beta}
\end{array}\right]=\frac{2}{3}\left[\begin{array}{ccc}
1 & -\frac{1}{2} & -\frac{1}{2} \\
0 & \frac{\sqrt{3}}{2} & -\frac{\sqrt{3}}{2}
\end{array}\right]\left[\begin{array}{l}
i_{a} \\
i_{b} \\
i_{c}
\end{array}\right]
$$

\section{Park Transformation:}

Here, the two axis stationary reference frame is converted to time invariant rotating reference frame as follows [54]:

$$
\left[\begin{array}{l}
i_{d} \\
i_{q}
\end{array}\right]=\left[\begin{array}{cc}
\cos \theta & \sin \theta \\
-\sin \theta & \cos \theta
\end{array}\right]\left[\begin{array}{l}
i_{\alpha} \\
i_{\beta}
\end{array}\right]
$$

Inverse Park Transformation:

The PI controllers give outputs of voltage components in rotating reference frame, so an inverse of the previous procedure is used to obtain the reference voltages in the stationary reference frame using the following equations [54]:

$$
\left[\begin{array}{l}
v_{\alpha} \\
v_{\beta}
\end{array}\right]=\left[\begin{array}{cc}
\cos \theta & \sin \theta \\
-\sin \theta & \cos \theta
\end{array}\right]\left[\begin{array}{l}
v_{d} \\
v_{q}
\end{array}\right]
$$

\section{Inverse Clarke Transformation:}

The two axis orthogonal reference frame is transformed to three phase stator reference frame with the help of following equations [54]:

$$
\left[\begin{array}{l}
v_{a} \\
v_{b} \\
v_{c}
\end{array}\right]=\left[\begin{array}{cc}
1 & 0 \\
-\frac{1}{2} & \frac{\sqrt{3}}{2} \\
-\frac{1}{2} & -\frac{\sqrt{3}}{2}
\end{array}\right]\left[\begin{array}{l}
v_{\alpha} \\
v_{\beta}
\end{array}\right]
$$




\subsection{Machine block}

A PMSM consists of wound stator, permanent magnet rotor construction and some internal or external instruments to detect rotor position. Frequency and amplitude of stator voltage reference can be controlled using the position feedback from sensing devices. The stator windings are energized by three phase stator currents which create a rotating electromagnetic field. A constant rotor flux is produced with the help of permanent magnets rigidly fixed to the rotating axis [55]. A torque is generated as a result of the interaction between stator and rotor fluxes, which rotates the rotor, giving useful mechanical output as shown in Figure 3.8 [56]. Maximum torque can be achieved by controlling the angle between the stator field and rotor magnetic field [55]. A fine tuning is required in the speed loop to produce minimum current under the same speed and torque conditions [56]. The rotor magnetic field and stator field must rotate at the same frequency for synchronous operation or the rotor will experience alternating positive and negative torque [55]. Due to this, problems such as mechanical vibration, noise and less than optimal torque production

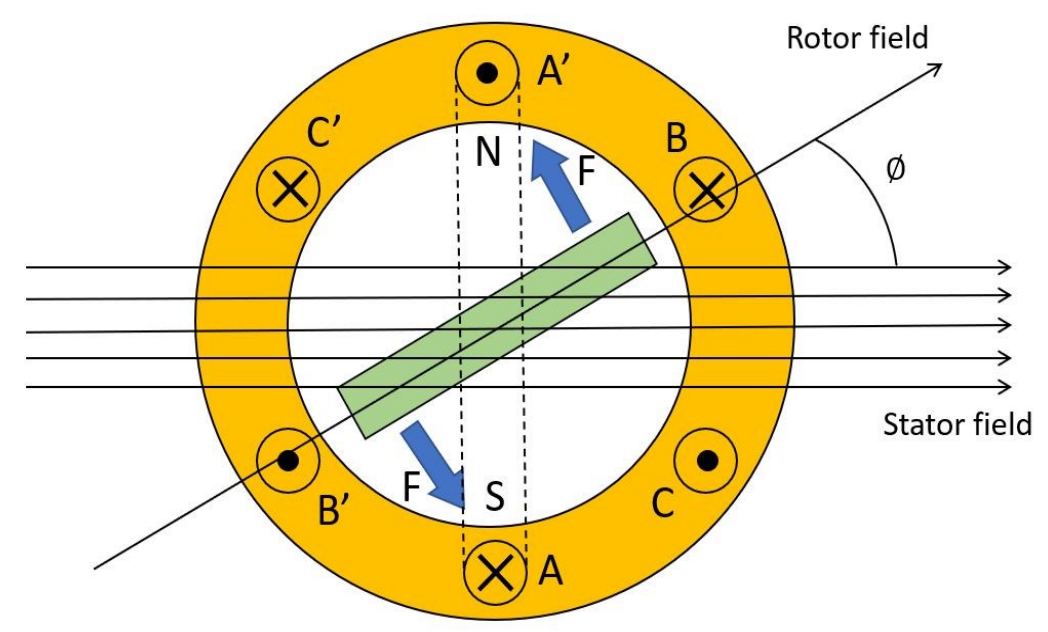

Figure 3.8: Interaction between stator flux and rotor flux in PMSM 
are encountered [55]. Highest mutual torque can be generated if the stator and rotor fields are kept orthogonal to each other. For this, correct information about the rotor position is required to produce the right stator field [55]. The resultant stator flux can be controlled if different stator phases are combined to give the required direction and magnitude to the stator field [55]. 


\section{Chapter 4}

\section{Proposed Universal Control Strategies}

\subsection{Vector Control}

\subsubsection{Overview}

The conventional field-oriented vector control strategy uses the Park transformation, as shown in Figure 2.2. The stator voltage equations in the $d-q$ reference frame are obtained from dynamic equations (3.3) and (3.4). A feedback signal of rotor speed is compared with the reference speed, which determines the $q$-axis current reference using the outer loop PI controller driven by the speed error [10]. The current loop control technique is developed using equations (3.3) and (3.4). The current references $i_{q(\text { ref })}$ (torque reference) and $i_{d(\text { ref })}$ (flux reference) are compared with the $i_{d}$ and $i_{q}$ components. The two PI controllers for $d-q$ axis current control give the voltage signals in the $d-q$ reference frame [10]. The controller gains of all the three standard PI controllers used here can be represented as given in Equations 4.1-4.3. The second proposed strategy called the simplified control is explained in section 4 which uses only two PI controllers driven by the speed the $d$-axis current error. Both these proposed control techniques aim to determine the PI controller gains in a simple way using some motor parameters.

The rotor position information is required to convert the $d$ - $q$ voltage commands into $v_{\alpha}$ and $v_{\beta}$ components, which are the inputs of the SVPWM [10]. The 3-phase inverter is driven by the outputs of the SVPWM block. Two motor phase currents are measured and are fed to the Clarke 
transformation module, giving the outputs $i_{\alpha}$ and $i_{\beta}$. These two components of the current act as the inputs to the Park transformation block which gives the currents in the $d-q$ rotating reference frame.

$$
\begin{gathered}
i_{q(r e f)}(t)=K_{p \omega} e_{\omega}(t)+K_{i \omega} \int_{0}^{t} e_{\omega}(t) d t \\
v_{d}(t)=K_{p d} e_{d}(t)+K_{i d} \int_{0}^{t} e_{d}(t) d t \\
v_{q}(t)=K_{p q} e_{q}(t)+K_{i q} \int_{0}^{t} e_{q}(t) d t
\end{gathered}
$$

where,

$$
\begin{aligned}
i_{q(\text { ref })}= & \text { output of speed PI controller, } K_{p \omega} \text { and } K_{i \omega} \text { represents the respective PI gains } \\
v_{d}= & \text { output of } i_{d} \text { PI controller, } K_{p d} \text { and } K_{i d} \text { represents the respective PI gains } \\
v_{q}= & \text { output of } i_{q} \text { PI controller, } K_{p q} \text { and } K_{i q} \text { represents the respective PI gains } \\
& \text { and } e_{\omega}, e_{d} \text { and } e_{q} \text { are the speed and } d-q \text { axis current errors respectively }
\end{aligned}
$$

\subsubsection{Proposed Universal Control Strategy}

A total of eight motors are used for the determination and validation of this proposed control scheme. These eight motors are arranged in the increasing order of their power ratings and they are represented as $\mathrm{M}_{1}, \mathrm{M}_{2}, \mathrm{M}_{3}, \ldots, \mathrm{M}_{8}$. In this paper, $\mathrm{PMSMs}$ up to $7.5 \mathrm{~kW}$ power ratings are used, consisting of both the interior and surface mounted types of PMSMs. Motors $\mathrm{M}_{1}, \mathrm{M}_{4}, \mathrm{M}_{6}$ and $\mathrm{M}_{8}$ are used for the generalization of this control technique, while the remaining four motors are used for verification purpose. The main aim of this control strategy is to obtain some mathematical equations to determine controller gains by interpolating generalized curves against motors' power ratings. For this interpolation, the first and last motors $M_{1}$ and $M_{8}$ are considered, while two 
motors, $\mathrm{M}_{4}$ and $\mathrm{M}_{6}$ are taken from in between the range, such that the generalized curves can also be applied to the other four validation motors.

In the vector control, the outer loop PI controller operates using the speed error, and the two current loop PI controllers are driven to maintain the $d-q$ axis reference currents. Considering the given topology, each motor needs to be tuned for six control gains for the three PI controllers. The three proportional gains for the speed and $d-q$ axis current control are denoted by $K_{p \omega}, K_{p d}$ and

Table 4.1: Parameters of all PMSMs

\begin{tabular}{|c|c|c|c|c|c|c|c|c|c|}
\hline Parameters & Symbol & $\mathbf{M}_{1}$ & $\mathbf{M}_{2}$ & $\mathbf{M}_{3}$ & $\mathrm{M}_{4}$ & M5 & $\mathbf{M}_{6}$ & $\mathbf{M}_{7}$ & M8 \\
\hline $\begin{array}{c}\text { Rated } \\
\text { power/(kW) }\end{array}$ & $p$ & 0.15 & 0.25 & 0.4 & 0.5 & 1.49 & 2 & 3.8 & 7.5 \\
\hline $\begin{array}{c}\text { Rated } \\
\text { speed/(rpm) }\end{array}$ & $\omega$ & 2400 & 4000 & 3000 & 3000 & 1125 & 1000 & 3000 & 1500 \\
\hline $\begin{array}{l}\text { Number of } \\
\text { pole pairs }\end{array}$ & $n_{p}$ & 2 & 5 & 4 & 4 & 6 & 4 & 6 & 4 \\
\hline $\begin{array}{l}\text { Stator } \\
\text { resistance/ } \\
(\Omega)\end{array}$ & $R_{S}$ & $\begin{array}{c}2.62 \times \\
10^{-3}\end{array}$ & 0.18 & 1.73 & 1.38 & 2.9 & 2.73 & 0.94 & 0.44 \\
\hline $\begin{array}{c}d \text {-axis stator } \\
\text { inductance/ } \\
(\mathrm{mH})\end{array}$ & $L_{d}$ & 0.23 & 0.25 & 3.46 & 3.7 & 5.43 & 14.5 & 7 & 8.39 \\
\hline $\begin{array}{l}q \text {-axis stator } \\
\text { inductance/ } \\
(\mathrm{mH})\end{array}$ & $L_{q}$ & 0.23 & 0.25 & 3.46 & 3.7 & 8.58 & 31.18 & 8.3 & 8.39 \\
\hline $\begin{array}{l}\text { Permanent } \\
\text { magnet } \\
\text { flux/ } \\
(\mathrm{Wb})\end{array}$ & $\psi$ & $\begin{array}{c}12.4 \times \\
10^{-3}\end{array}$ & $\begin{array}{c}15.9 \times \\
10^{-3}\end{array}$ & 0.03 & $\begin{array}{r}4.5 \times \\
10^{-2}\end{array}$ & 0.043 & 0.55 & 0.25 & 0.168 \\
\hline $\begin{array}{l}\text { Moment of } \\
\text { inertia/ } \\
\left(\mathrm{kg} \cdot \mathrm{m}^{2}\right)\end{array}$ & $J$ & $9 \times 10^{-5}$ & $\begin{array}{c}2.91 \times \\
10^{-4}\end{array}$ & $\begin{array}{c}3 \times \\
10^{-4}\end{array}$ & $\begin{array}{l}5.5 \times \\
10^{-4}\end{array}$ & $\begin{array}{c}4.5 \times \\
10^{-4}\end{array}$ & 0.011 & $\begin{array}{c}2 \times \\
10^{-3}\end{array}$ & $\begin{array}{l}1.5 \times \\
10^{-3}\end{array}$ \\
\hline $\begin{array}{l}\text { Viscous } \\
\text { friction } \\
\text { coefficient/ } \\
\text { (N.m.s/rad) }\end{array}$ & $B$ & $\begin{array}{l}1.3 \times \\
10^{-5}\end{array}$ & $\begin{array}{c}3.63 \times \\
10^{-4}\end{array}$ & $\begin{array}{l}5.8 \times \\
10^{-4}\end{array}$ & $\begin{array}{l}7.2 \times \\
10^{-4}\end{array}$ & $\begin{array}{l}1.2 \times \\
10^{-4}\end{array}$ & 0.02 & $\begin{array}{c}3.8 \times \\
10^{-2}\end{array}$ & $\begin{array}{c}4 \times \\
10^{-5}\end{array}$ \\
\hline
\end{tabular}


$K_{p q}$ respectively, while the integral gains are represented as $K_{i \omega}, K_{i d}$ and $K_{i q}$ for the same. Motors $\mathrm{M}_{1}, \mathrm{M}_{4}, \mathrm{M}_{6}$ and $\mathrm{M}_{8}$ are tuned, and the lower and upper limits of each of the gains are found using an empirical study. The final values of the lower and upper limit gains for the speed and $d-q$ axis currents are determined only if their relative percentage errors are almost zero at steady states and less than $1 \%$ during the transients. Perfect tracking of the reference value by the actual value with very little overshoots is also considered while calculating the final gain values. These same criteria are also considered in section 4.2 for the simplified control method to determine all its control gains. These same criteria are also considered in section 4.2 for the simplified control method to determine all its control gains. To show the tracking accuracy relative to other generalization motors, rotor speed percentage error (\%) is presented in Figure 4.1. Here, it can be seen that tracking error increases with the size of the motor. Although motor $\mathrm{M}_{8}$ has the highest error among all the four PMSMs, its tracking error remains in an acceptable range. To analyze further its tracking performance, Figure 4.2 shows the speed and $d-q$ axis currents. The desired speed signal is taken as a step response of a critically damped second-order system. At $5 \mathrm{~s}$, the speed increases to $500 \mathrm{rpm}$ with no load. Once at a steady state, full load is applied and the speed is increased again to the motor's rated speed of $1500 \mathrm{rpm}$. Then, the speed goes back to $500 \mathrm{rpm}$ before the load is suddenly released and the motor is brought to the full stop. Figure 4.2 reveals a high tracking accuracy and a fast response when overcoming the applied load. The overshoot under such condition is negligible, i.e., $0.013 \%$. It is worthwhile mentioning that less overshoot is observed for the other three PMSMs.

Here, the main aim of this control strategy is to generate some mathematical equations which can calculate every controller gain just by using its motor power rating. The power rating is the 
most easily available information on any motor's nameplate, and thus, it is chosen as a variable to calculate every control gain. First, for every motor, the lowest and highest possible values for each of the given control gains are plotted against its power rating. Then, in the next step, a generalized curve is to be formulated in the region enclosed between these values. For every control gain, a set of linear and nonlinear curves are plotted in the bottom, center, and upper parts of the available

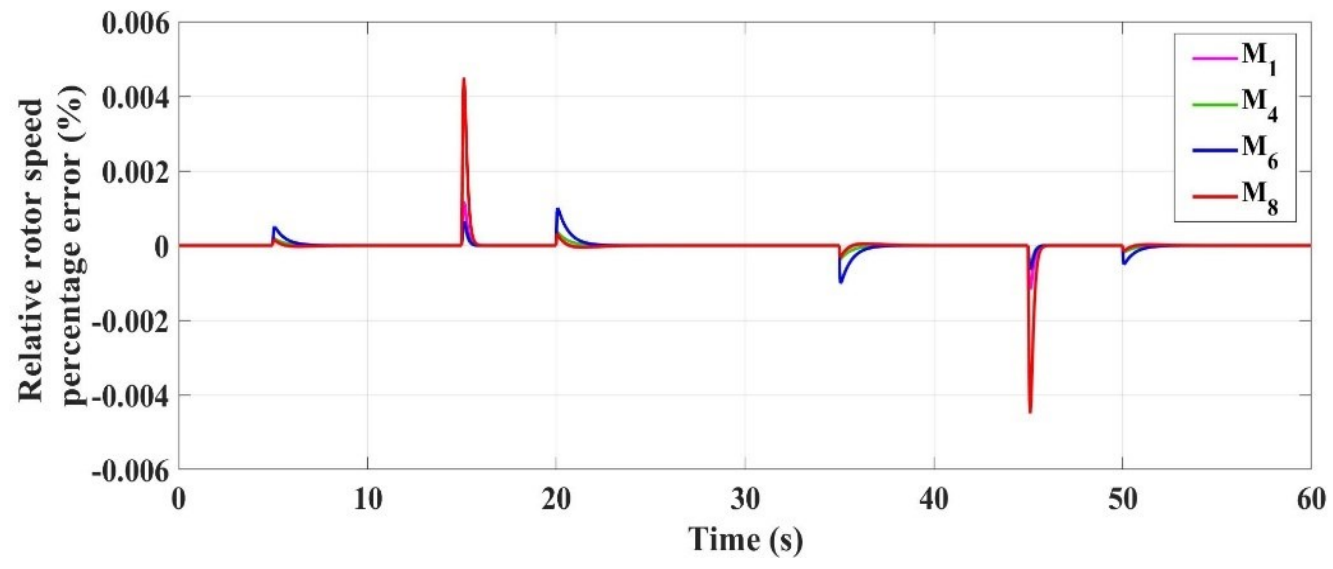

Figure 4.1: Relative rotor speed percentage errors (\%)

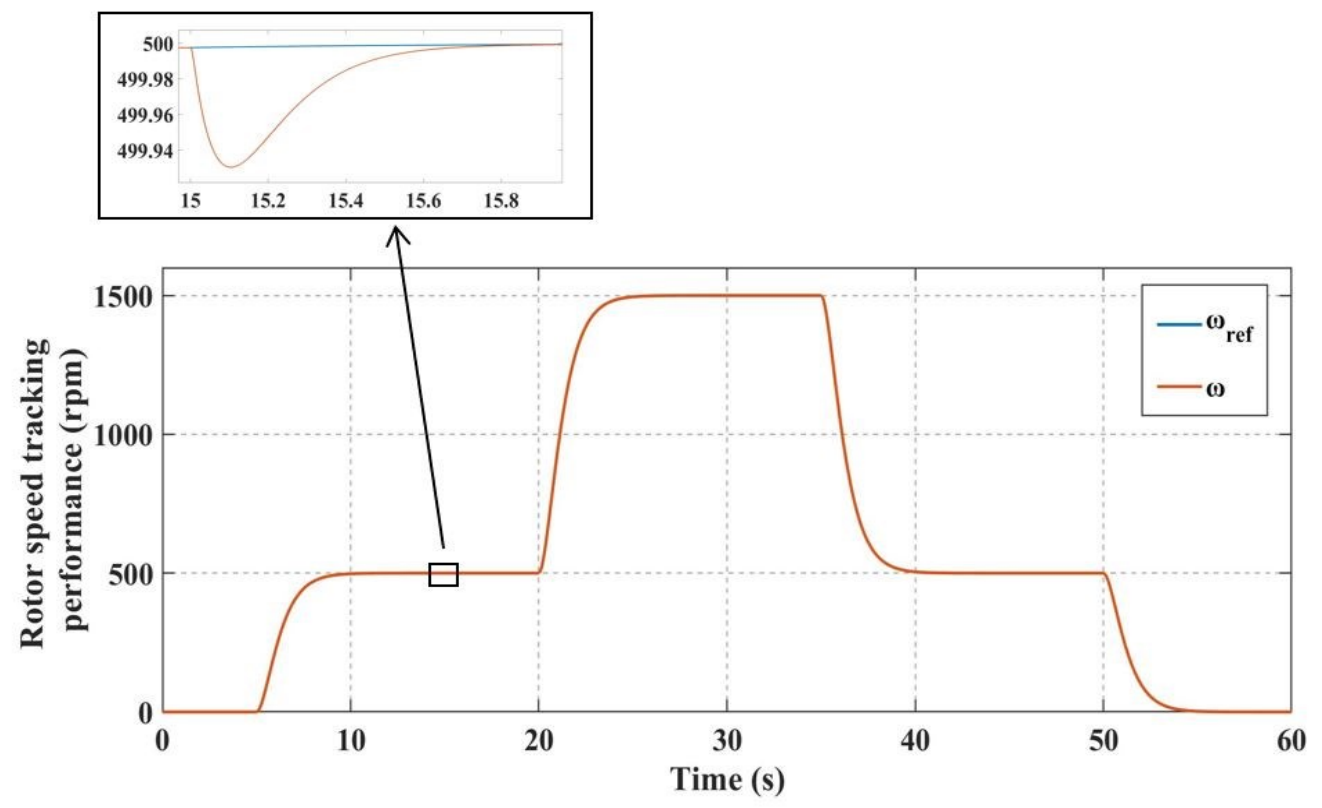

(a) 


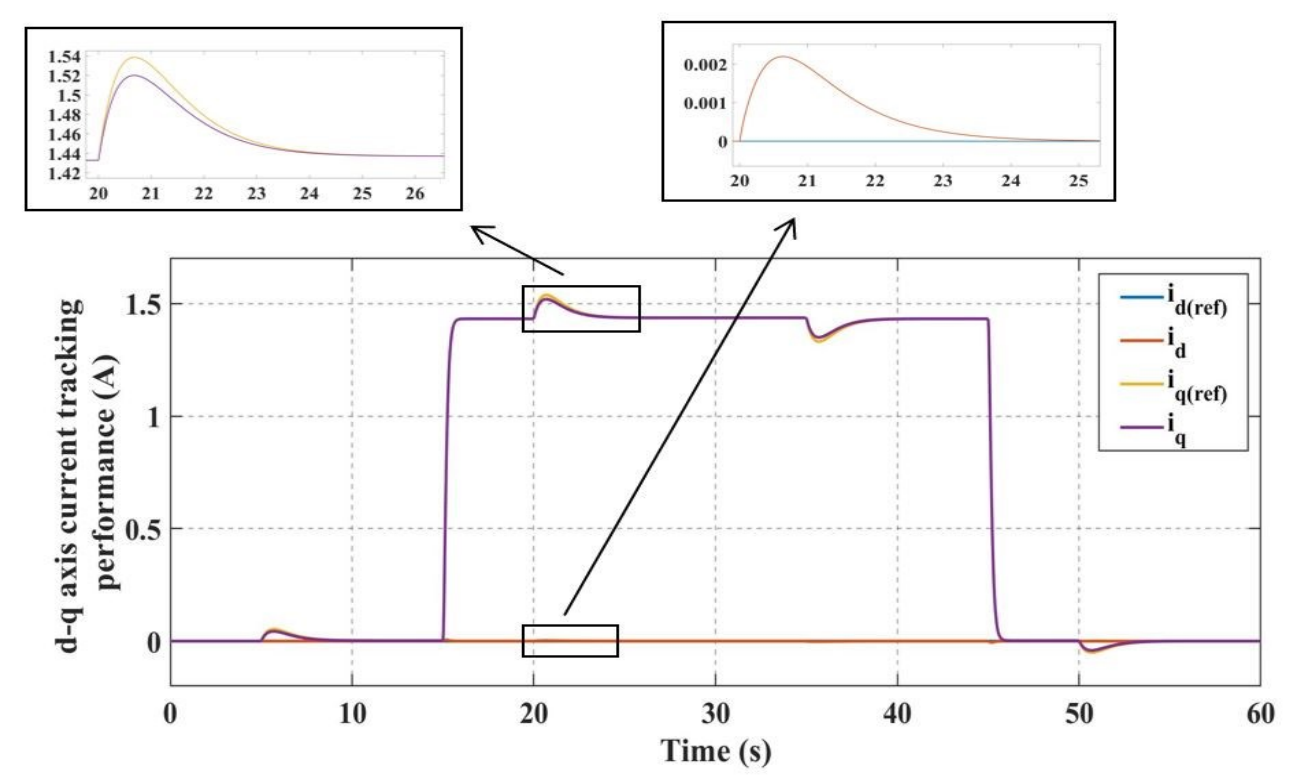

(b)

Figure 4.2: Motor $\mathrm{M}_{8}$ tracking performance. (a) Speed; (b) $d-q$ axis currents

region, and their corresponding mathematical expressions are formed. Using the power ratings of the four motors; $\mathrm{M}_{1}, \mathrm{M}_{4}, \mathrm{M}_{6}$, and $\mathrm{M}_{8}$, all these formulated equations are used to determine their respective control gains. These calculated gains are used for their respective motors and the control performance of their speed and $d-q$ axis current tracking are observed. The main goal to draw these generalized curves in the lower, center, and higher regions is to determine which region gives the best performing control gains. In all the given linear and nonlinear equations, the power rating is the only variable while the rest are some constant values. These constant values are altered after every trial by an empirical study until the gains calculated from these equations give the best control performance of all those PMSMs. It is found that the gains calculated using the nonlinear curves give better accuracy compared to the linear ones. One of the nonlinear curves from the three regions is finalized, whose calculated gains give the best accuracy in the speed and $d-q$ axis current tracking. 
It can be seen that the generalized curves of the proportional gains are in the bottom region while those of the integral gains can be found in the upper part. Moreover, for every gain, such curves can be approximated to some square root or quadratic mathematical functions. These equations can be applied to both the interior and surface mounted types of PMSMs. This same procedure is also followed in section 4.2 for the simplified control scheme to determine the most optimal generalized curve for every controller gain. Figure 4.3 shows the plots of all the six control gains w.r.t motor power ratings and their respective generalized curves.
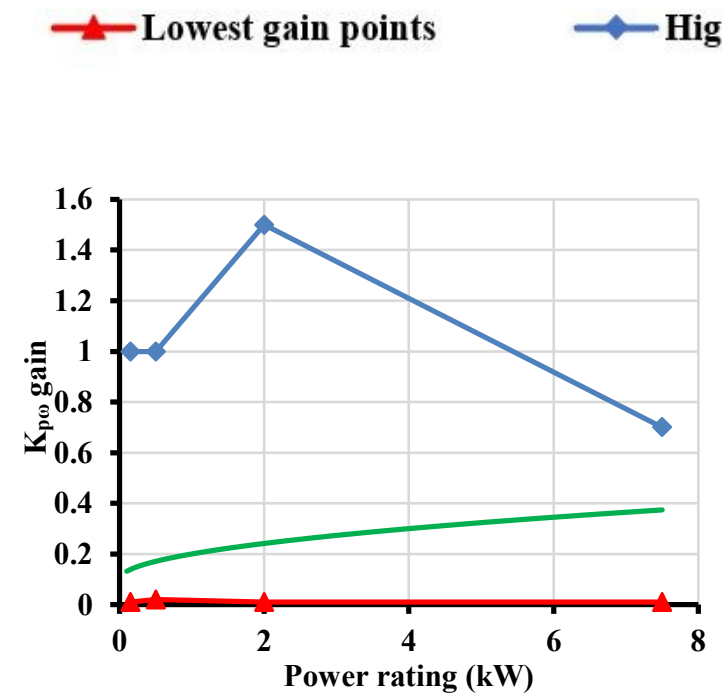

(a)

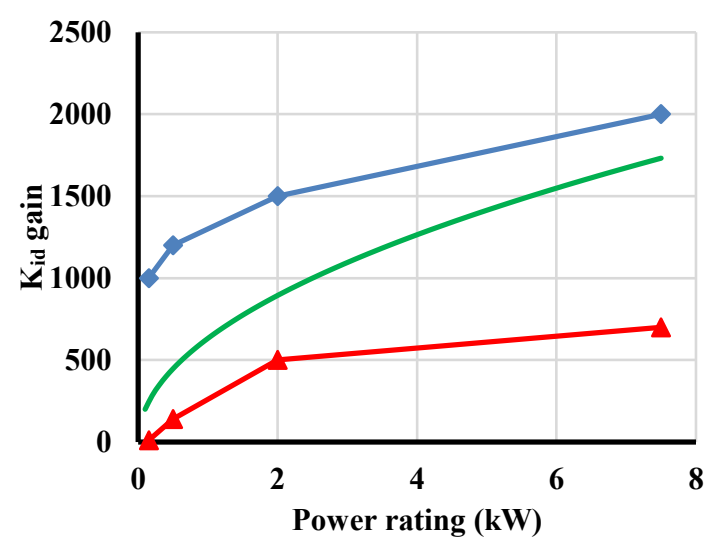

(c)

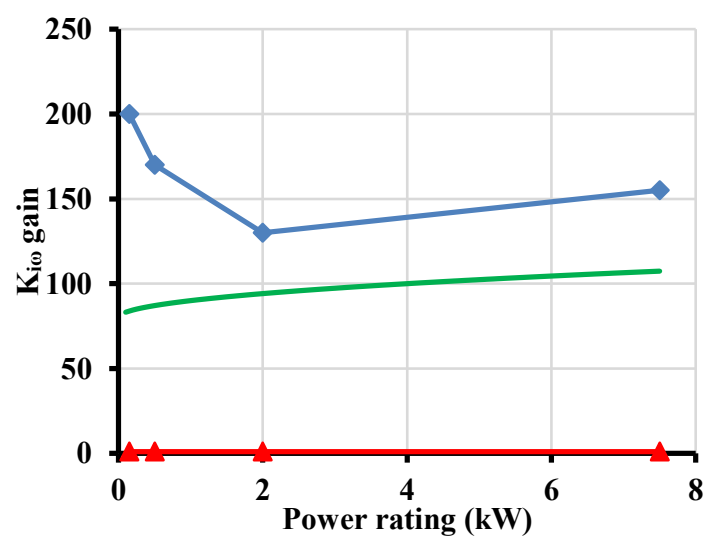

(b)

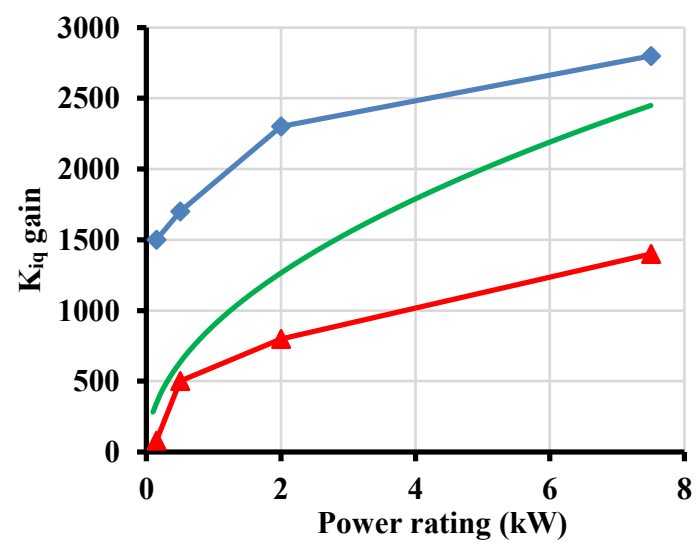

(d) 


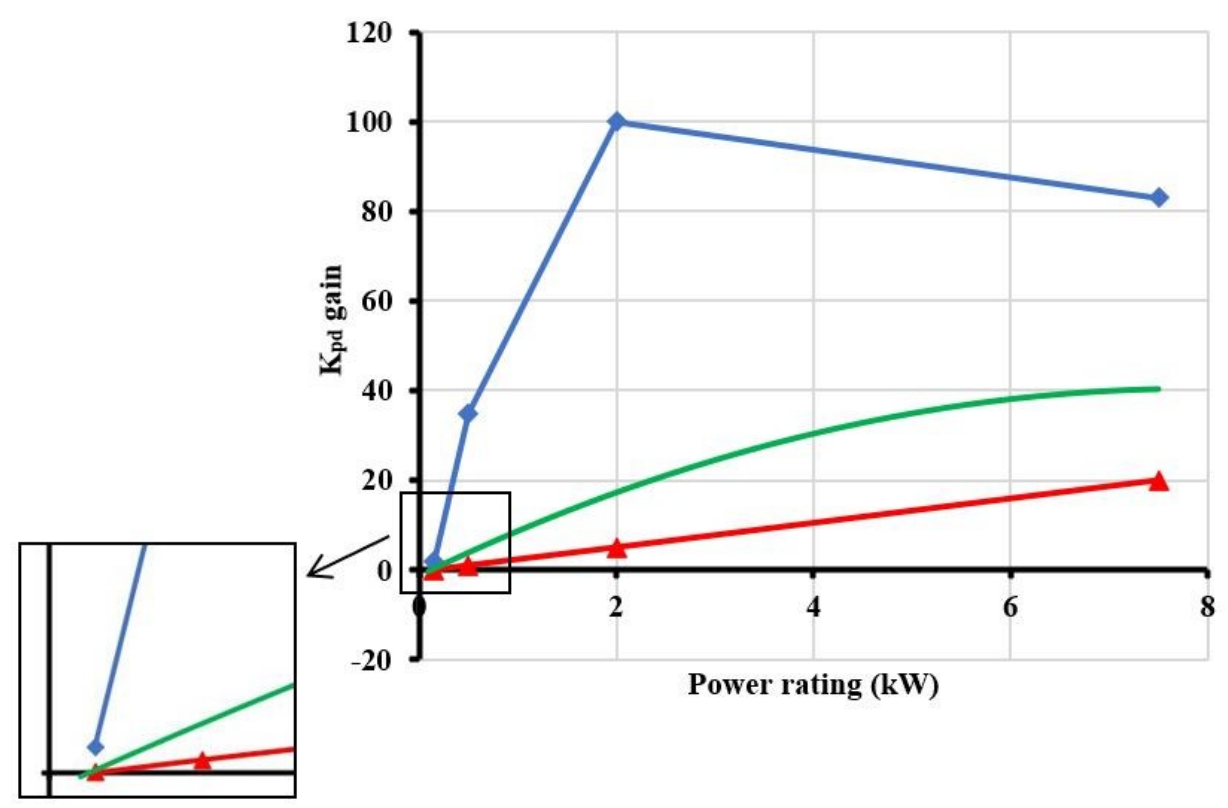

(e)

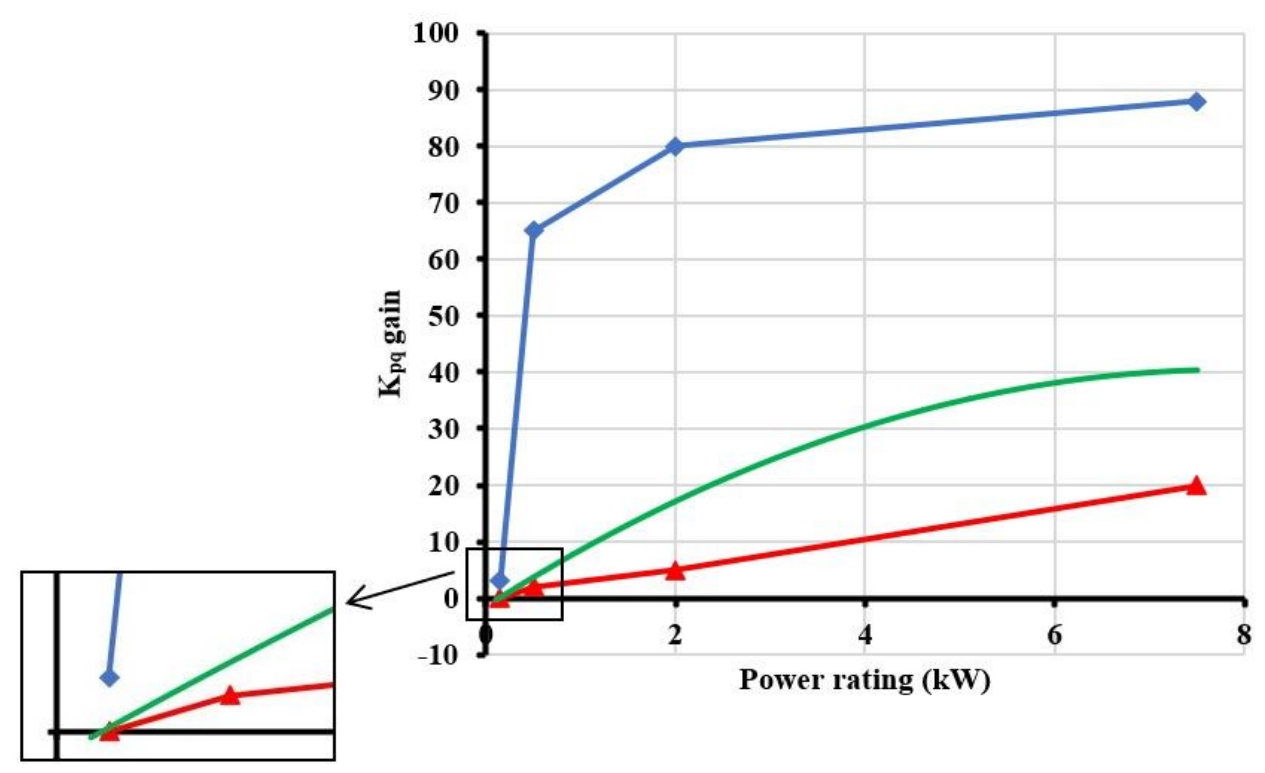

(f)

Figure 4.3: PI control gains versus motor power ratings. (a) $K_{p \omega}$; (b) $K_{i \omega}$; (c) $K_{i d}$; (d) $K_{i q}$; (e) $K_{p d}$; (f) $K_{p q}$. 
The nonlinear generalized curve allows better precision in the tracking of the speed and $d-q$ axis currents which is also justified by the non-linear nature of the PMSM's dynamics. Moreover, for every gain, such curves can be approximated to some square root or quadratic mathematical functions as follows:

$$
\begin{gathered}
K_{p \omega}=\sqrt{0.01 p}+0.1 \\
K_{i \omega}=\sqrt{100 p}+80 \\
K_{p d}=-0.67 p^{2}+10.62 p-1.35 \\
K_{i d}=\sqrt{4 p \times 10^{5}} \\
K_{p q}=-0.67 p^{2}+10.62 p-1.35 \\
K_{i q}=\sqrt{8 p \times 10^{5}}
\end{gathered}
$$

where $p$ is the power rating in $\mathrm{kW}$. It can be seen from Figure 4.3 (e) and (f) that both these curves are almost identical. Thus, the same mathematical expression can be applied to both $K_{p d}$ and $K_{p q}$ gains as depicted in Equations (4.6) and (4.8). To verify the working of these mathematical expressions for PI control tuning, motors $\mathrm{M}_{2}, \mathrm{M}_{3}, \mathrm{M}_{5}$ and $\mathrm{M}_{7}$ are used for experimentation. The simulation results of these four motors in MATLAB/Simulink are discussed in Chapter 5.

\subsection{Simplified Control}

\subsubsection{Overview}

The modeling equations of PMSM play a vital role in its control strategy and one such equation is used for the working of the simplified control method. The simplified control is an attempt to 


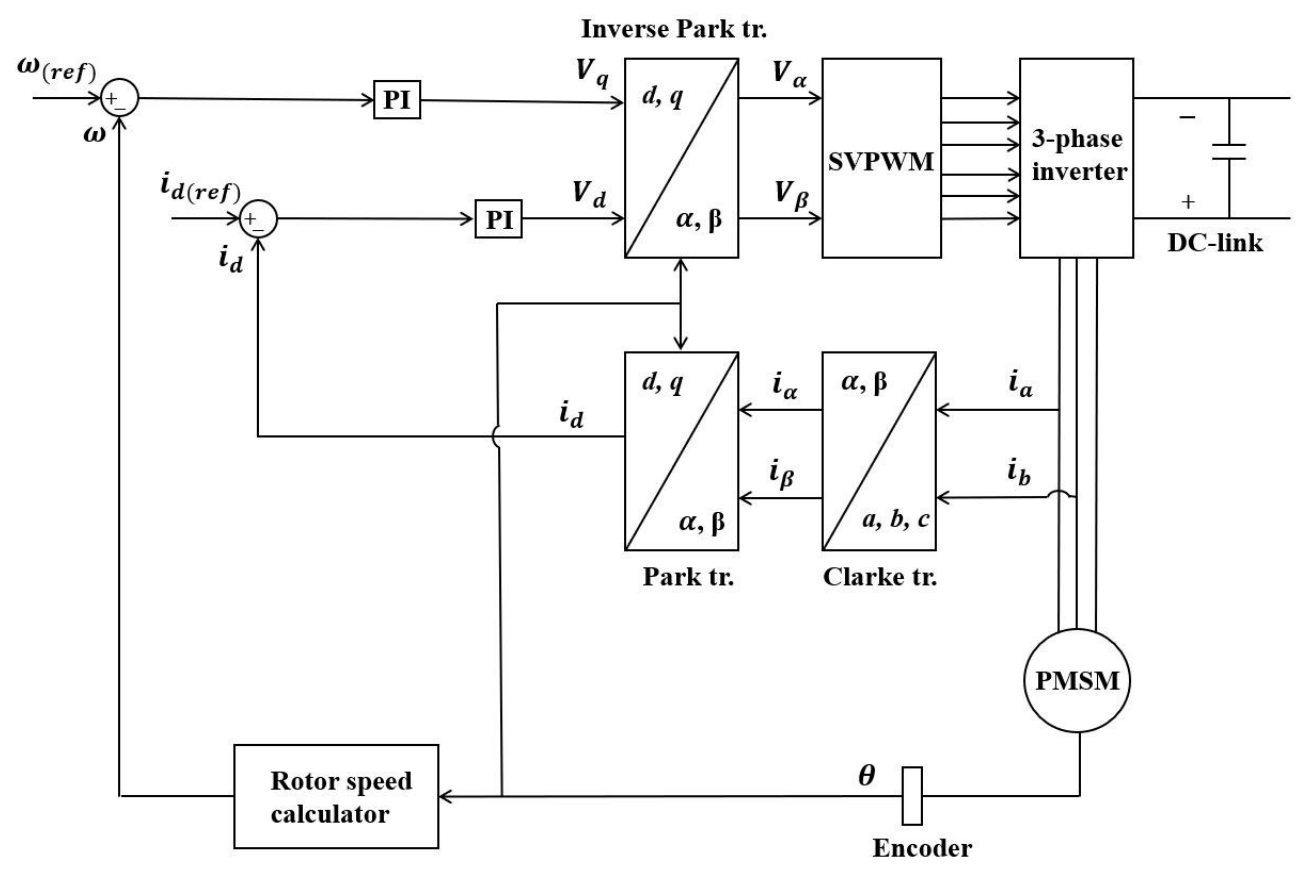

Figure 4.4: Simplified Control Scheme

make the vector control scheme less complicated by eliminating the need for cascaded PI controllers. The only difference between the vector control and simplified control is the way of calculating the voltage component $v_{q}$. Considering Equation (3.4), it can be seen that the value of $v_{q}$ mainly depends on the product of $n_{p}$ and $\psi$, as the rest of the terms hold insignificant values due to low $R_{s}, L_{d}$ and $L_{q}$. As shown in Figure 4.4, the outer loop PI controller uses the speed error to generate the output of $q$-axis voltage component $v_{q}$. This strategy nullifies the need for the second PI controller driven by the $i_{q}$ current error to calculate $v_{q}$. Thus, in this method only two PI controllers are used which are driven by the speed the $d$-axis current error. The outputs of these two PI controllers can be represented by Equations (4.10) and (4.11) to achieve optimal control.

$$
v_{q}(t)=K_{p \omega} e_{\omega}(t)+K_{i \omega} \int_{0}^{t} e_{\omega}(t) d t
$$




$$
v_{d}(t)=K_{p d} e_{d}(t)+K_{i d} \int_{0}^{t} e_{d}(t) d t
$$

where,

$$
\begin{aligned}
v_{q}= & \text { output of speed PI controller, } K_{p \omega} \text { and } K_{i \omega} \text { represents the respective PI gains } \\
v_{d}= & \text { output of } i_{d} \text { PI controller, } K_{p d} \text { and } K_{i d} \text { represents the respective PI gains } \\
& \text { and } e_{\omega}, e_{d} \text { are the speed and } d \text {-axis current errors respectively }
\end{aligned}
$$

\subsubsection{Proposed Universal Control Strategy}

To establish a relationship between the $n_{p} \psi$ product and control gains, all the PMSMs are arranged in the increasing order of $n_{p} \psi$ product values. Thus, the motors are arranged in the order of $\mathrm{M}_{1}$, $\mathrm{M}_{2}, \mathrm{M}_{3}, \mathrm{M}_{4}, \mathrm{M}_{5}, \mathrm{M}_{8}, \mathrm{M}_{7}$ and $\mathrm{M}_{6}$ for the testing and validation of this control scheme. Voltage component $v_{q}$ is obtained as an output of the speed error PI controller instead of the inner loop PI controller, which uses the $i_{q}$ current error. As a result, the PI controller driven by the $i_{q}$ the current error gets eliminated. This makes the overall control structure less complex by getting rid of the cascaded controllers which are difficult to tune. Thus, four control gains are required to be tuned for the speed and $i_{d}$ current error PI controllers. Motors $\mathrm{M}_{1}, \mathrm{M}_{4}, \mathrm{M}_{8}$ and $\mathrm{M}_{6}$ are tuned using an empirical study, and their lowest and highest control gain points are plotted w.r.t the $n_{p} \psi$ product values. To show the accuracy of those four generalization motors while finalizing their gain values, a plot of their relative rotor speed percentage errors (\%) is mentioned in Figure 4.5. The speed and current tracking performance of motor $\mathrm{M}_{8}$ is shown in Figure 4.6 to verify its control precision. Although motor $\mathrm{M}_{8}$ yields the highest overshoot, i.e., $0.28 \%$, it is still in a low range. The average values of the lower and higher limit gain points of the respective motors are used to get appropriate results. 


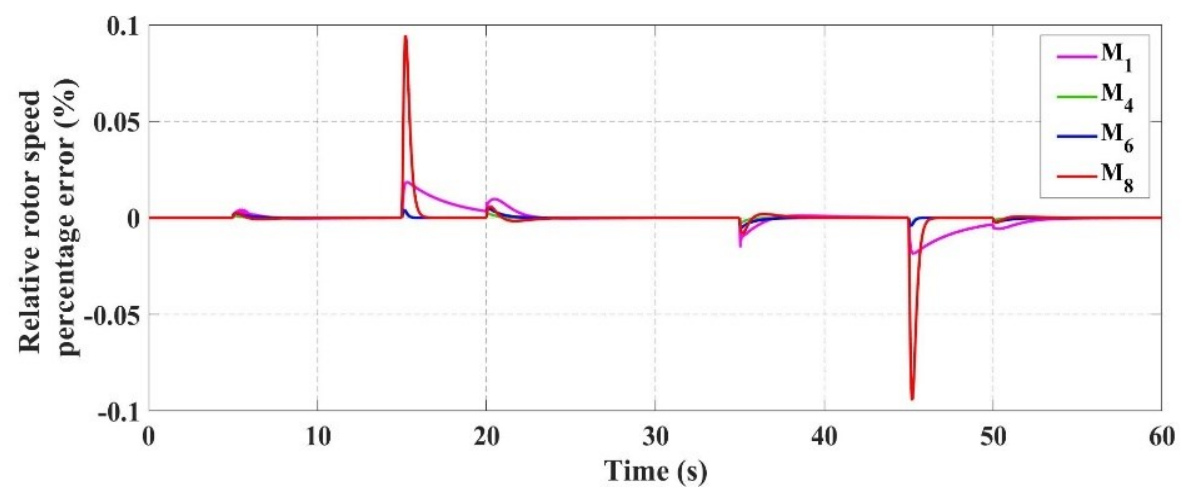

Figure 4.5: Relative rotor speed percentage errors (\%)

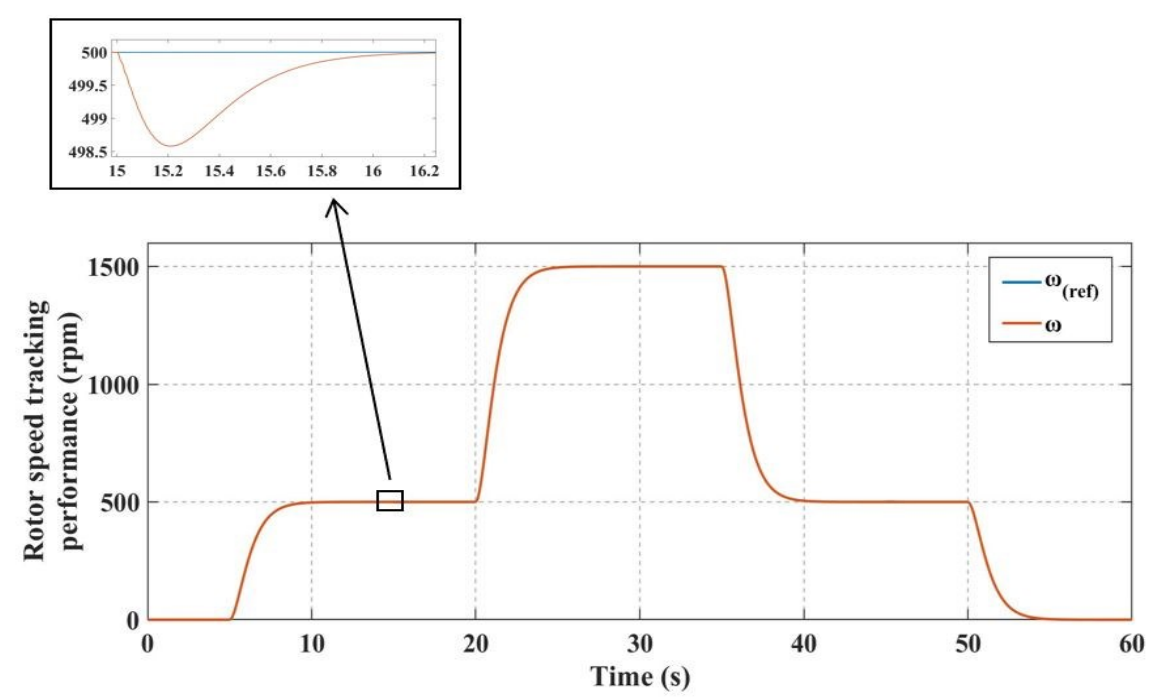

(a)

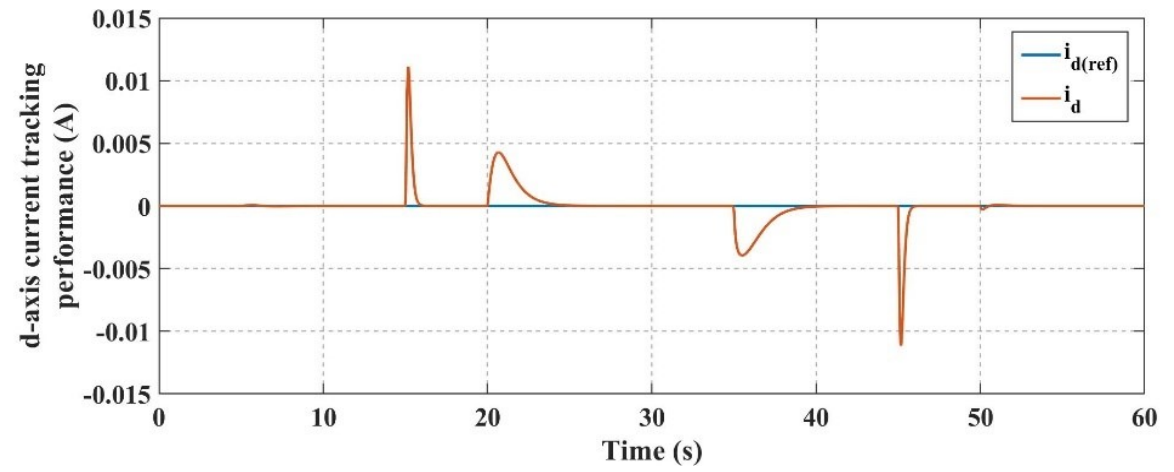

(b)

Figure 4.6: Motor $\mathrm{M}_{8}$ tracking performance. (a) Speed; (b) $d-q$ axis currents 
Unlike the vector control, a generalized nonlinear curve cannot be formulated due to the irregular nature of the highest gain points. Thus, a linear curve is formed for every distinctive gain and further analyzed for its accuracy. The validation motors are used for determining the reliability of this control strategy which is discussed in section 5. Figure 4.7 represents all the graphs of the control gains plotted against the $n_{p} \psi$ product values in detail.

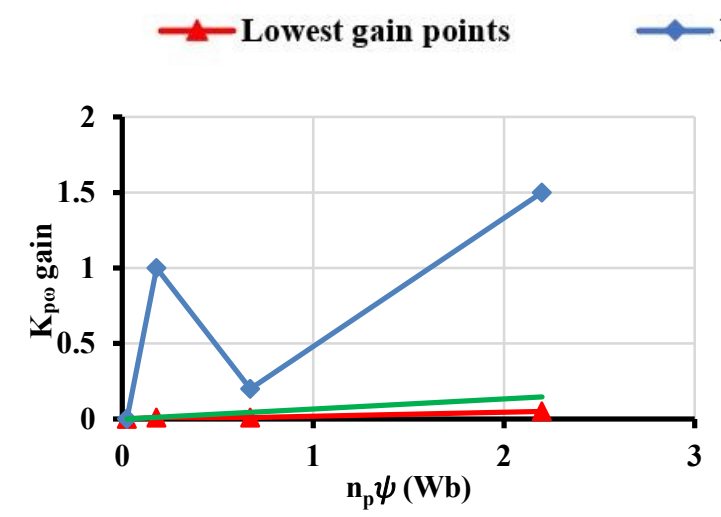

(a)

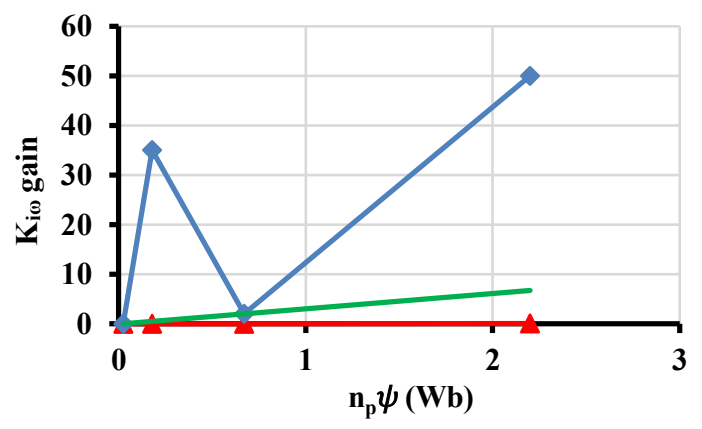

(b)

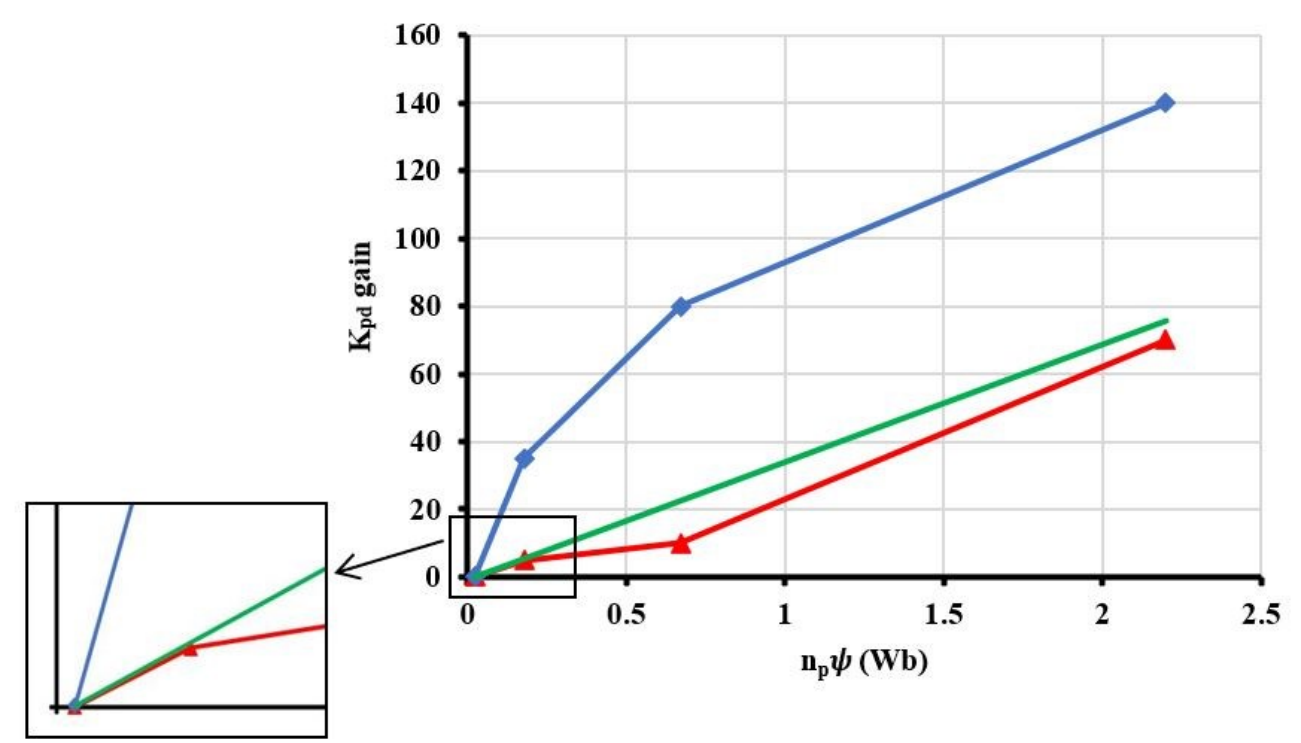

(c) 


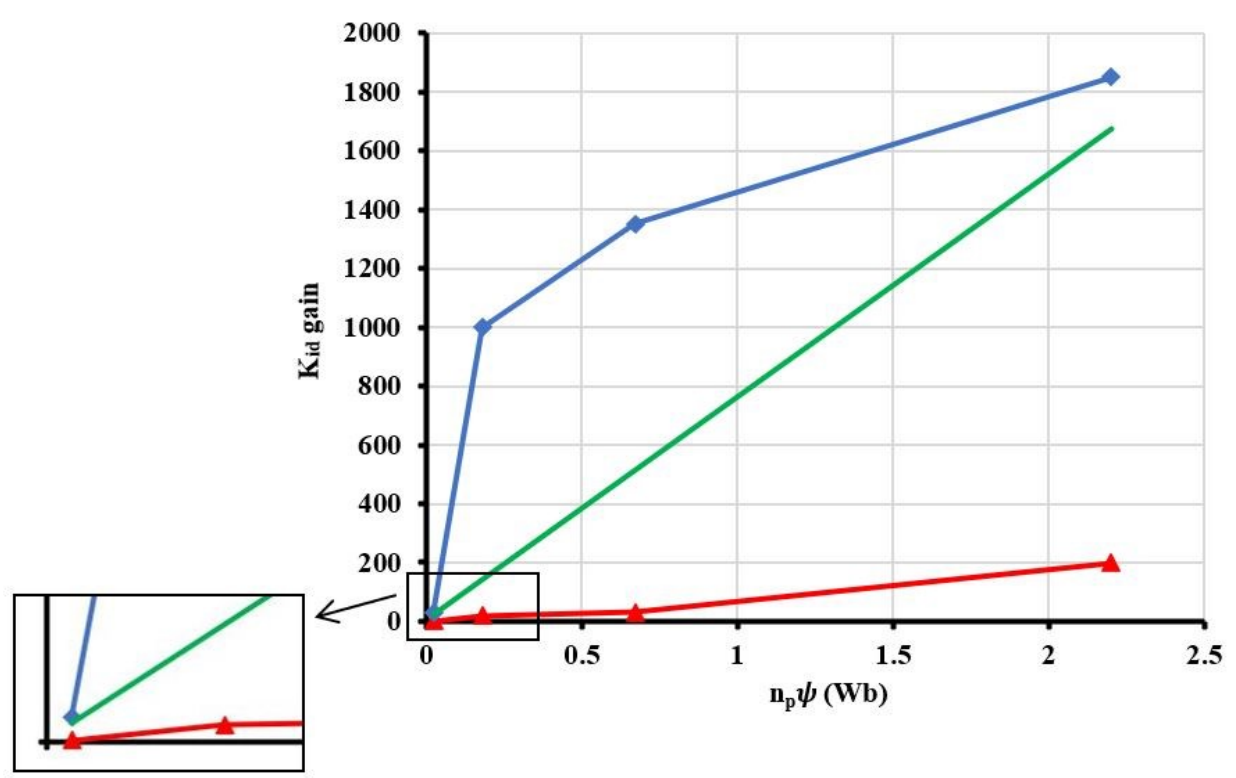

(d)

Figure 4.7: Plots of PI control gains versus $n_{p} \psi$ product values. (a) $K_{p \omega}$; (b) $K_{i \omega}$; (c) $K_{p d}$;

(d) $K_{i d}$.

The generalized curves given in Figure 4.7 can be represented in the form of simple straight line equations as follows:

$$
\begin{gathered}
K_{p \omega}=0.067\left(n_{p} \psi\right)-\left(6.6 \times 10^{-4}\right) \\
K_{i \omega}=3.09\left(n_{p} \psi\right)-0.076 \\
K_{p d}=34.73\left(n_{p} \psi\right)-0.76 \\
K_{i d}=760\left(n_{p} \psi\right)-3.66
\end{gathered}
$$

To verify the functioning of these mathematical expressions for obtaining PI control gains, motors $\mathrm{M}_{2}, \mathrm{M}_{3}, \mathrm{M}_{5}$ and $\mathrm{M}_{7}$ are used and simulated in the MATLAB/Simulink software. 


\section{Chapter 5}

\section{Machines Controller Tuning Evaluation}

This chapter investigates the effectiveness of the two proposed gain tuning approaches using the vector and simplified control. The process of determining the gains is done offline and does not add to the complexity of the control system. Motors $\mathrm{M}_{2}, \mathrm{M}_{3}, \mathrm{M}_{5}$ and $\mathrm{M}_{7}$ are evaluated using the gains determined by both the proposed offline tuning methods consisting of some simple linear and nonlinear mathematical equations. Table 4.1 tabulates the parameters of all the eight PMSMs used in this paper, of which five are surface mounted and three are interior mounted PMSMs. Motors $\mathrm{M}_{2}, \mathrm{M}_{3}, \mathrm{M}_{5}$ and $\mathrm{M}_{7}$ are evaluated using the gains determined by both the proposed control strategies discussed in Chapter 4. These four motors are examined under different load conditions, and the variations in the $d-q$ axis currents and the rotor speed are monitored. The actual values of $\omega, i_{d}$ and $i_{q}$ are compared with their reference values, and the respective errors are plotted to discuss the feasibility of the given control strategies. Figure 5.1 depicts the above mentioned errors for the vector control approach for all the four PMSMs considered for validation.

For the vector control approach, the maximum rotor speed error w.r.t the rated speed is noted as $0.0027 \%$ for motor $\mathrm{M}_{5}$. Also, the errors in $d-q$ axis currents are very minimal, which proves the high accuracy of this tuning method. For the simplified control approach, only the rotor speed error and the $d$-axis current error is mentioned in Figure 5.2 as the $q$-axis current is not taken into account. It can be seen that the maximum percentage error in the rotor speed is $0.85 \%$, which 


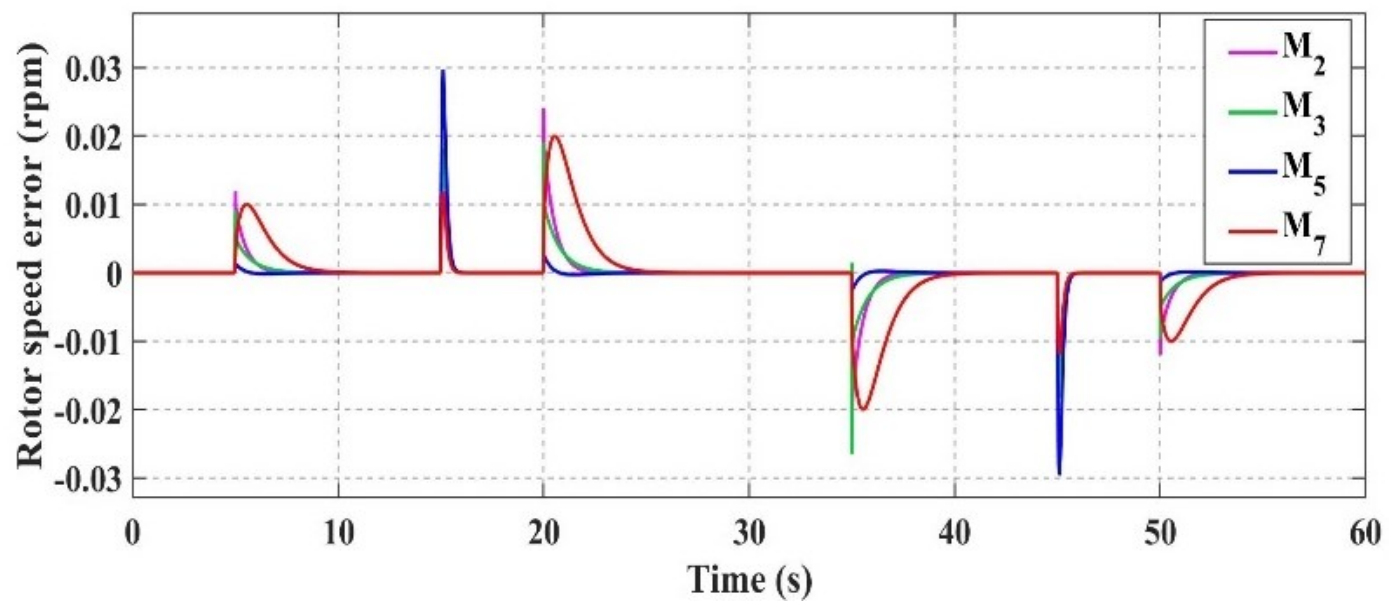

(a)

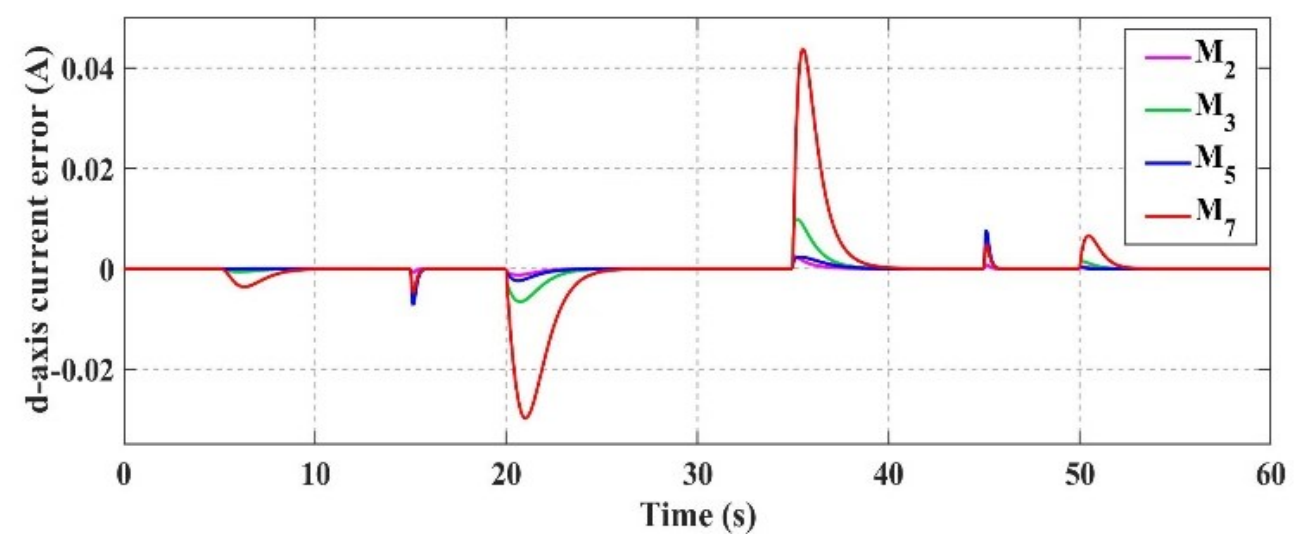

(b)

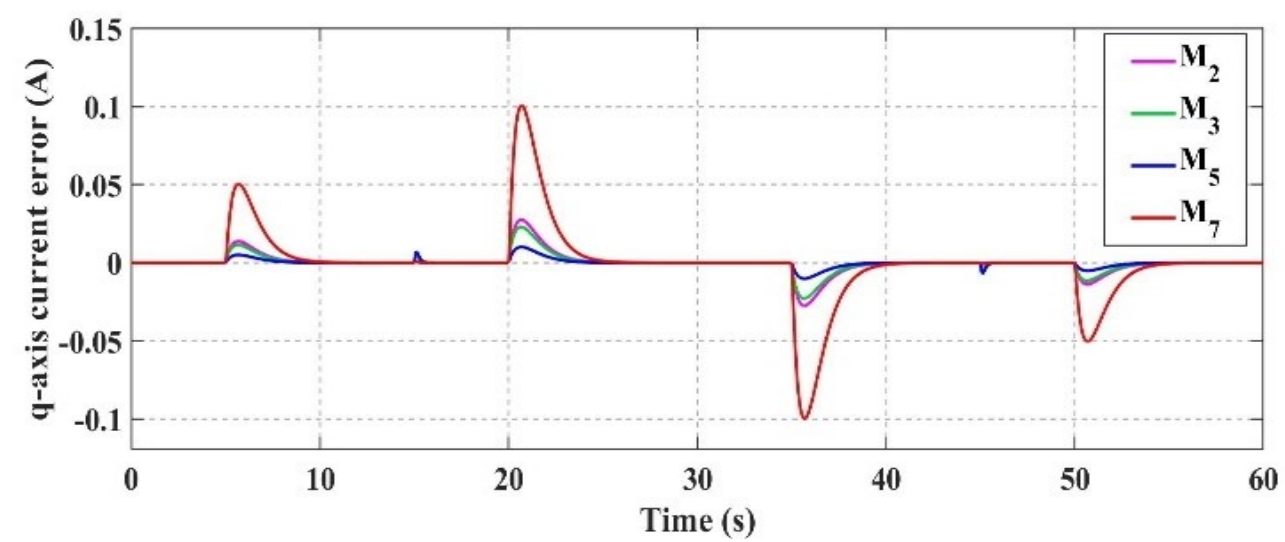

(c)

Figure 5.1: Errors measured in the vector control method. (a) Rotor speed error; (b) $d$ axis current error; (c) $q$-axis current error 


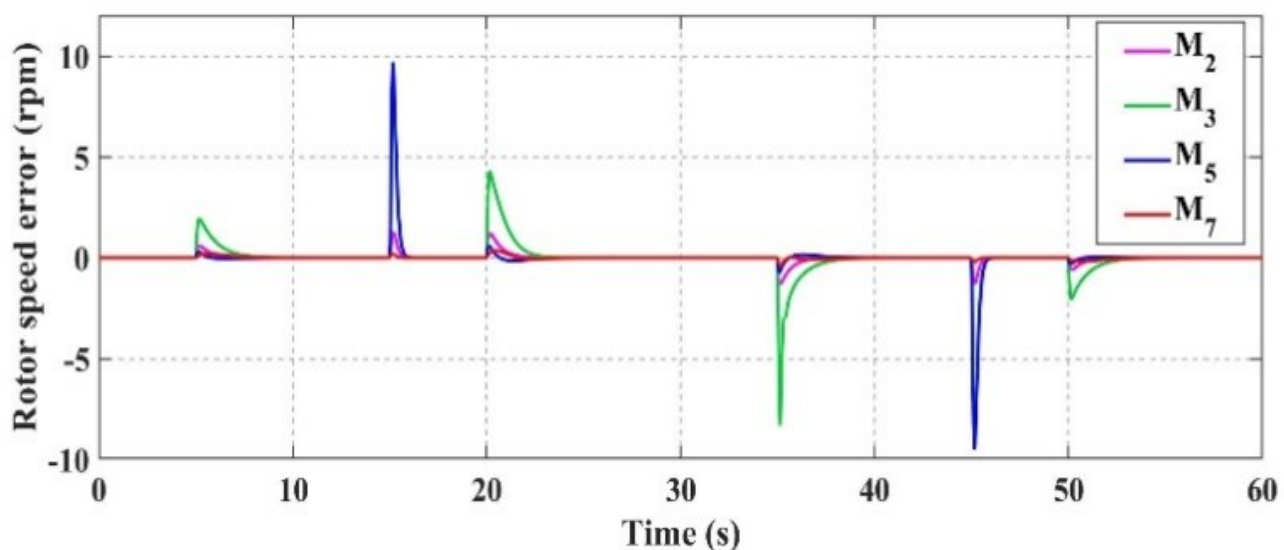

(a)

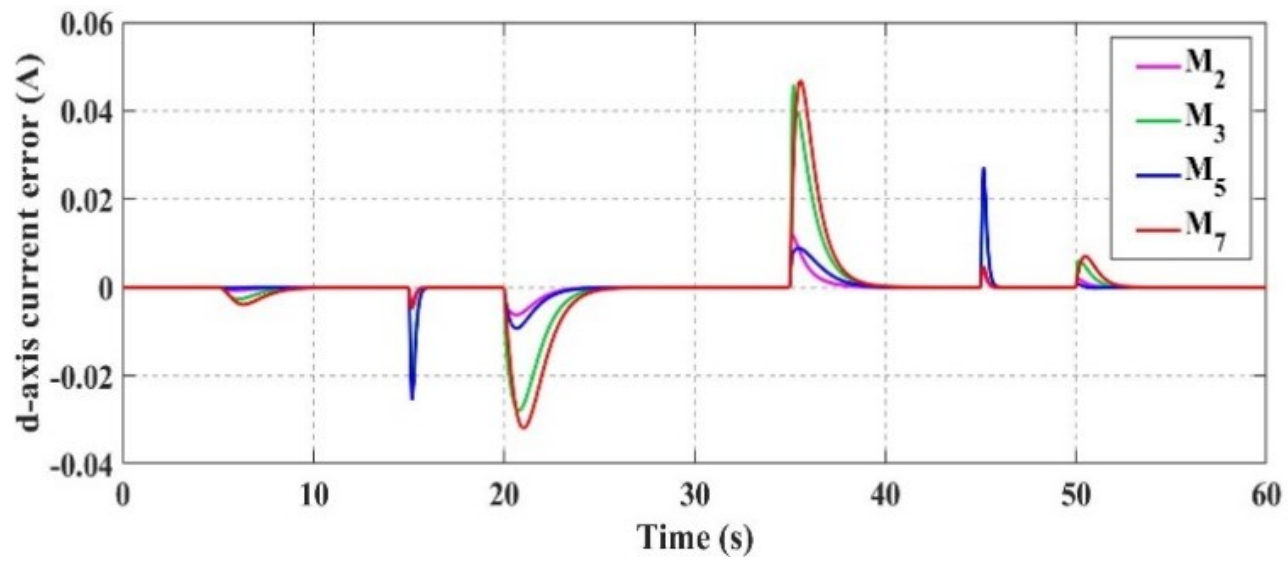

(b)

Figure 5.2: Errors measured in simplified control method. (a) Rotor speed error;

(b) $d$-axis current error

occurs for motor $\mathrm{M}_{5}$ and the $d$-axis current error is also not significant. To compare the accuracy of both the control techniques, the rotor speed errors in percentage $(\%)$ are represented in Figure 5.3. From Table 5.1, it can be seen that the vector control strategy has better overall performance and accuracy compared to the simplified control. 


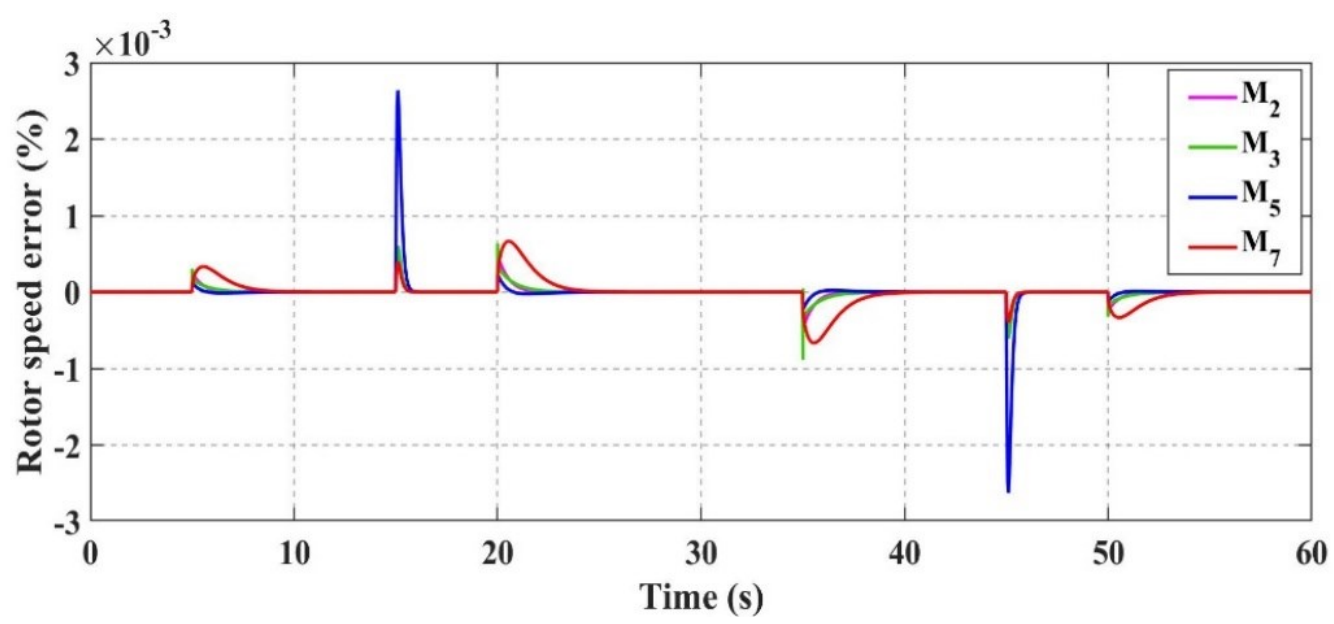

(a)

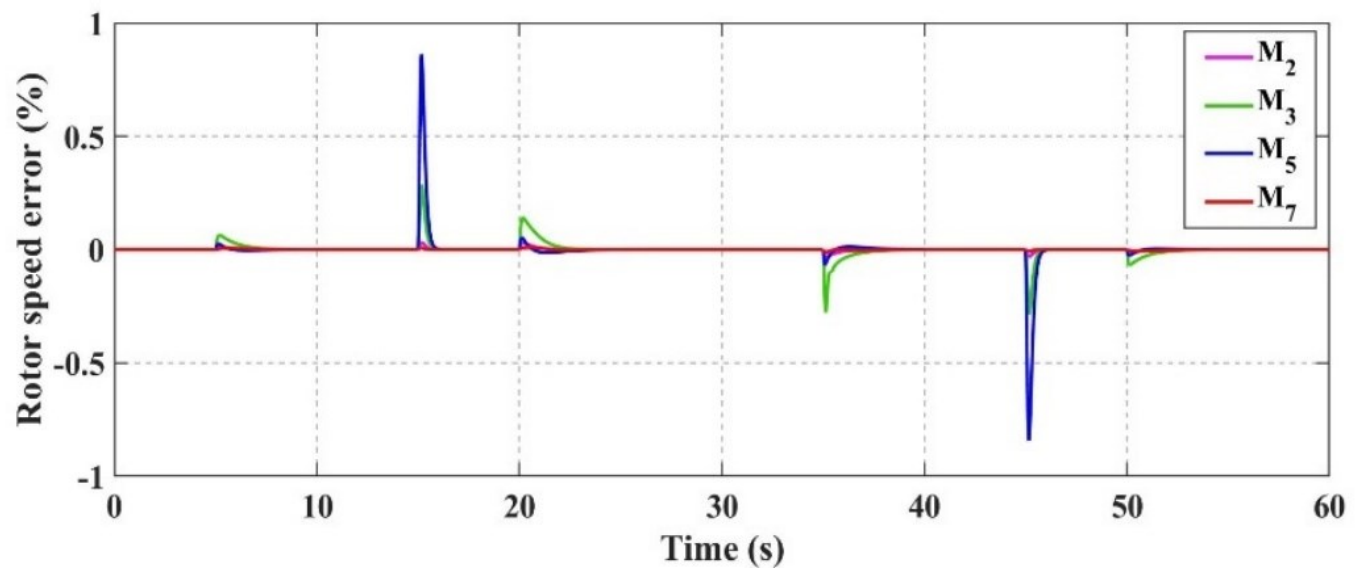

(b)

Figure 5.3: Rotor speed errors in percentage (\%). (a) Vector control; (b) Simplified control

Table 5.1: Comparison of Average Rotor Speed Error (\%)

\begin{tabular}{ccc}
\hline Validation Motors & Vector control & Simplified control \\
\hline $\mathrm{M}_{2}$ & $1.65 \times 10^{-5}$ & $1.5 \times 10^{-3}$ \\
$\mathrm{M}_{3}$ & $1.86 \times 10^{-5}$ & $9.4 \times 10^{-3}$ \\
$\mathrm{M}_{5}$ & $2.91 \times 10^{-5}$ & 0.01 \\
$\mathrm{M}_{7}$ & $6.3 \times 10^{-5}$ & $8 \times 10^{-4}$ \\
\hline
\end{tabular}


Although, both the proposed methods give good results with minimum errors, it is required to validate these techniques under the effect of motor parameter variations. When a motor is used in any application, its parameters' values change due to the increment of temperature. This also affects the performance of the motor which needs to be taken into consideration during its operation. It is found that the stator resistance increases with the increase in temperature, which degrades the motor output [43], while the magnetic flux decreases with the increase in magnet temperature [44]. When the temperature increases up to $80^{\circ} \mathrm{C}$, the stator resistance can vary by nearly $20 \%$ [43], while there is a decrement of magnetic flux by $10 \%$ under almost the same operating conditions [44]. These factors are considered and the Integral Absolute Errors (IAE) for the speed tracking of all the validation motors are calculated in Table 5.2 under the influence of parameter variations. Integral Absolute Error can be defined as:

$$
I A E=\int_{0}^{t}\left|e_{\omega}(t)\right| d t
$$

where $e_{\omega}(t)$ represents the speed error.

Table 5.2: IAE comparison under varying motor parameters

\begin{tabular}{|c|c|c|c|c|c|c|}
\hline \multirow{2}{*}{$\begin{array}{c}\text { Validation } \\
\text { motors }\end{array}$} & \multicolumn{2}{|c|}{ IAE (Nominal) } & \multicolumn{2}{|c|}{ IAE $\left(120 \% R_{s}\right)$} & \multicolumn{2}{|c|}{ IAE $(90 \% \psi)$} \\
\hline & $\begin{array}{l}\text { Vector } \\
\text { control }\end{array}$ & $\begin{array}{c}\text { Simplified } \\
\text { control }\end{array}$ & $\begin{array}{l}\text { Vector } \\
\text { control }\end{array}$ & $\begin{array}{c}\text { Simplified } \\
\text { control }\end{array}$ & $\begin{array}{l}\text { Vector } \\
\text { control }\end{array}$ & $\begin{array}{c}\text { Simplified } \\
\text { control }\end{array}$ \\
\hline $\mathrm{M}_{2}$ & 198.38 & 17908.32 & 198.38 & 21455.19 & 220.59 & 19910.53 \\
\hline $\mathrm{M}_{3}$ & 167.11 & 84645.15 & 167.1 & 101574.14 & 185.72 & 94050.17 \\
\hline $\mathrm{M}_{5}$ & 98.28 & 35542.29 & 98.28 & 42573.7 & 108.42 & 39429.06 \\
\hline $\mathrm{M}_{7}$ & 566.69 & 7625.47 & 566.69 & 9565.21 & 629.52 & 8318.39 \\
\hline
\end{tabular}


All these results show that the vector control strategy has better precision and accuracy compared to the simplified control method, along with a little disadvantage of using some complex mathematical expressions for the determination of the control gains. 


\section{Chapter 6}

\section{Conclusions and Future Work}

\subsection{Conclusions}

This thesis proposed two gain tuning methods for the control of the PMSMs with minimum information of its prior system dynamics. Both these strategies make use of generalized mathematical expressions to determine the values of all the required control gains. First, the vector control approach is used to obtain some mathematical equations consisting of the respective control gain and the motor power rating as the two variables. The accuracy of this method is verified when some new PMSMs are simulated using the calculated control gains from these equations. In the second method, the simplified control strategy is used, based on the PMSM modeling equations. The generated mathematical expressions from this approach make use of the product of the number of pole pairs and flux linkage to find the required control gains. This method has the advantage of using only two PI controllers due to the elimination of the typical cascaded control structure. Furthermore, this method uses simple linear mathematical equations compared to the complex expressions derived from the vector control approach. This method is also verified by simulating the new PMSMs and calculating the rotor speed and $d$-axis current errors. It is found that the vector control technique has better accuracy compared to the simplified control method. Compared to the existing conventional control gain tuning methods, the proposed strategies are easier to implement and less time consuming in the real system. However, only PMSMs up to 
power ratings of $7.5 \mathrm{~kW}$ are considered in this paper, so further investigation is needed for motors with higher ratings.

\subsection{Future Work}

This research demonstrated that a proposed gain tuning approach using some mathematical expressions was successful in meeting the control requirements of PMSMs with uncertain system's dynamics. However, there are several possible opportunities for further research as follows:

1. In this thesis, the control gains are calculated using interpolation of generalized curves with the help of some mathematical equations. However, this research can't provide an insight on how the control gains are related to the PMSM's dynamic model. Future work may envision deriving the control gains analytically from the PMSM's mathematical model.

2. The interpolation and formation of the generalized curves take considerable time manually. However, future scope may include the use of neural networks to formulate the best generalized curves, giving minimum errors.

3. In this thesis, the motor parameters like power rating, no. of pole pairs and flux linkage are used as the variables to determine the control gains. But, these gains can vary drastically depending on the load applied to the PMSMs. To overcome this limitation, one more variable in the form of motor inertia can be incorporated in those generalized mathematical expressions to find more accurate controller gains.

4. Results showing the machine performance under parametric uncertainties are analyzed but additional investigation is required to fully assess the system's robustness. 
5. This thesis has only considered PMSMs up to power ratings of $7.5 \mathrm{~kW}$ and has produced very good results. But there is still scope to further explore this area by including more PMSMs with higher power ratings. PMSMs giving high output power are used in many fields such as industrial mills, medium size cargo vessels and HVAC systems. Thus, some research in this domain would yield better results in many real-life applications.

6. Another opportunity to explore this field would be to include other types of electrical motors along with the PMSMs. Various types of induction motors, DC motors and stepper motors have their own advantages and disadvantages and are used in many specific applications. So, a generalized control approach which can be applied to any type of motor would be a major breakthrough in the field of electrical engineering. 


\section{List of References}

[1] S. Sakunthala, R. Kiranmayi and P. N. Mandadi, "A Review on Speed Control of Permanent Magnet Synchronous Motor Drive Using Different Control Techniques," 2018 International Conference on Power, Energy, Control and Transmission Systems (ICPECTS), Chennai, 2018, pp. 97-102, doi: 10.1109/ICPECTS.2018.8521574.

[2] V. M. Bida, D. V. Samokhyalov and F. S. Al-Mahturi, "PMSM vector control techniques - A survey,” 2018 IEEE Conference of Russian Young Researchers in Electrical and Electronic Engineering (EIConRus), Moscow, 2018, pp. 577-581, doi: 10.1109/EIConRus.2018.8317164

[3] Y. Kung, Risfendra, Y. Lin and L. Huang, "FPGA-based sensorless controller for PMSM drives using sliding mode observer and phase locked loop," 2016 International Conference on Applied System Innovation (ICASI), Okinawa, 2016, pp. 1-4, doi:10.1109/ICASI.2016.7539798.

[4] S. Chen and H. Hoai, "Studying an Adaptive Fuzzy PID Controller for PMSM with FOC based on MATLAB Embedded Coder," 2019 IEEE International Conference on Consumer Electronics - Taiwan (ICCE-TW), YILAN, Taiwan, 2019, pp. 1-2, doi: 10.1109/ICCETW46550.2019.8991743.

[5] M. B. B. Sharifian, T. Herizchi and K. G. Firouzjah, "Field oriented control of permanent magnet synchronous motor using predictive space vector modulation," 2009 IEEE 
Symposium on Industrial Electronics \& Applications, Kuala Lumpur, 2009, pp. 574-579, doi: 10.1109/ISIEA.2009.5356385.

[6] [Online] https://in.element14.com/motor-control-permanent-magnet-sync-motor-pmsmtechnology

[7] F. Korkmaz, İ. Topaloğlu, M. F. Çakir and R. Gürbüz, "Comparative performance evaluation of FOC and DTC controlled PMSM drives," 4th International Conference on Power Engineering, Energy and Electrical Drives, Istanbul, 2013, pp. 705-708, doi: 10.1109/PowerEng.2013.6635696.

[8] P. Sala-Perez, S. Galceran-Arellano and D. Montesinos-Miracle, "A sensorless stable V/f control method for a five-phase PMSM," 2013 15th European Conference on Power Electronics and Applications (EPE), Lille, 2013, pp. 1-10, doi: 10.1109/EPE.2013.6631943.

[9] K. Yang, X. Yang, H. Xie, Y. Liu, Y. Zhang and X. Wei, "Stable sensorless V/f and $\cos \varphi=1$ control for permanent magnet synchronous motor drives," 2014 17th International Conference on Electrical Machines and Systems (ICEMS), Hangzhou, 2014, pp. 3564-3568, doi: 10.1109/ICEMS.2014.7014107.

[10] G. Xie, K. Lu, S. K. Dwivedi, J. R. Rosholm and F. Blaabjerg, "Minimum-Voltage Vector Injection Method for Sensorless Control of PMSM for Low-Speed Operations," in IEEE Transactions on Power Electronics, vol. 31, no. 2, pp. 1785-1794, Feb. 2016, doi: 10.1109/TPEL.2015.2426200.

[11] M. Konghirun and L. Xu, "A Fast Transient-Current Control Strategy in Sensorless VectorControlled Permanent Magnet Synchronous Motor," in IEEE Transactions on Power Electronics, vol. 21, no. 5, pp. 1508-1512, Sept. 2006, doi: 10.1109/TPEL.2006.882419. 
[12] S. Li, H. Won, X. Fu, M. Fairbank, D. C. Wunsch and E. Alonso, "Neural-Network Vector Controller for Permanent-Magnet Synchronous Motor Drives: Simulated and HardwareValidated Results," in IEEE Transactions on Cybernetics, vol. 50, no. 7, pp. 3218-3230, July 2020, doi: 10.1109/TCYB.2019.2897653.

[13] S. Fartash Toloue, S. H. Kamali and M. Moallem, "Multivariable sliding-mode extremum seeking PI tuning for current control of a PMSM," in IET Electric Power Applications, vol. 14, no. 3, pp. 348-356, 3 2020, doi: 10.1049/iet-epa.2019.0033.

[14] In-Cheol Baik, Kyeong-Hwa Kim and Myung-Joong Youn, "Robust nonlinear speed control of PM synchronous motor using boundary layer integral sliding mode control technique," in IEEE Transactions on Control Systems Technology, vol. 8, no. 1, pp. 47-54, Jan. 2000, doi: $10.1109 / 87.817691$.

[15] D. Liang, J. Li, R. Qu and W. Kong, "Adaptive Second-Order Sliding-Mode Observer for PMSM Sensorless Control Considering VSI Nonlinearity," in IEEE Transactions on Power Electronics, vol. 33, no. 10, pp. 8994-9004, Oct. 2018, doi: 10.1109/TPEL.2017.2783920.

[16] Mohamed, Y.A.I. Design and Implementation of a Robust Current-Control Scheme for a PMSM Vector Drive With a Simple Adaptive Disturbance Observer. IEEE Transactions on Industrial Electronics 2007, 54, 1981-1988.

[17] T. Türker, U. Buyukkeles and A. F. Bakan, "A Robust Predictive Current Controller for PMSM Drives," in IEEE Transactions on Industrial Electronics, vol. 63, no. 6, pp. 39063914, June 2016, doi: 10.1109/TIE.2016.2521338. 
[18] S. Carpiuc and C. Lazar, "Fast Real-Time Constrained Predictive Current Control in Permanent Magnet Synchronous Machine-Based Automotive Traction Drives," in IEEE Transactions on Transportation Electrification, vol. 1, no. 4, pp. 326-335, Dec. 2015, doi: 10.1109/TTE.2015.2482223.

[19] W. Wang, Y. Fan, S. Chen and Q. Zhang, "Finite control set model predictive current control of a five-phase PMSM with virtual voltage vectors and adaptive control set," in CES Transactions on Electrical Machines and Systems, vol. 2, no. 1, pp. 136-141, March 2018, doi: 10.23919/TEMS.2018.8326460.

[20] G. Prior and M. Krstic, "Quantized-Input Control Lyapunov Approach for Permanent Magnet Synchronous Motor Drives," in IEEE Transactions on Control Systems Technology, vol. 21, no. 5, pp. 1784-1794, Sept. 2013, doi: 10.1109/TCST.2012.2212246.

[21] H. Liu and S. Li, "Speed Control for PMSM Servo System Using Predictive Functional Control and Extended State Observer," in IEEE Transactions on Industrial Electronics, vol. 59, no. 2, pp. 1171-1183, Feb. 2012, doi: 10.1109/TIE.2011.2162217.

[22] A. Formentini, A. Trentin, M. Marchesoni, P. Zanchetta and P. Wheeler, "Speed Finite Control Set Model Predictive Control of a PMSM Fed by Matrix Converter," in IEEE Transactions on Industrial Electronics, vol. 62, no. 11, pp. 6786-6796, Nov. 2015, doi: 10.1109/TIE.2015.2442526.

[23] N. Xuan-Mung, S.K. Hong, "Improved Altitude Control Algorithm for Quadcopter Unmanned Aerial Vehicles,” Appl. Sci. 2019, 9, 2122, https://doi.org/10.3390/app9102122. 
[24] A. L. Salih, M. Moghavvemi, H. A. F. Mohamed and K. S. Gaeid, "Modelling and PID controller design for a quadrotor unmanned air vehicle," 2010 IEEE International Conference on Automation, Quality and Testing, Robotics (AQTR), Cluj-Napoca, 2010, pp. 1-5, doi: 10.1109/AQTR.2010.5520914.

[25] N. Xuan-Mung, S. K. Hong, N. P. Nguyen, L. N. N. T. Ha and T. -L. Le, "Autonomous Quadcopter Precision Landing Onto a Heaving Platform: New Method and Experiment," in IEEE Access, vol. 8, pp. 167192-167202, 2020, doi: 10.1109/ACCESS.2020.3022881.

[26] E. Grassi and K. Tsakalis, "PID controller tuning by frequency loop-shaping: application to diffusion furnace temperature control," in IEEE Transactions on Control Systems Technology, vol. 8, no. 5, pp. 842-847, Sept. 2000, doi: 10.1109/87.865857.

[27] Kiyong Kim and R. C. Schaefer, "Tuning a PID controller for a digital excitation control system," in IEEE Transactions on Industry Applications, vol. 41, no. 2, pp. 485-492, MarchApril 2005, doi: 10.1109/TIA.2005.844368.

[28] D. Park, H. Yu, N. Xuan-Mung, J. Lee, S. K. Hong, "Multicopter PID Attitude Controller Gain Auto-tuning through Reinforcement Learning Neural Networks,” International Conference on Control and Robot Technology 2019, 80-84, https://doi.org/10.1145/3387304.3387327.

[29] C. C. Hang and K. K. Sin, "On-line auto tuning of PID controllers based on the crosscorrelation technique," in IEEE Transactions on Industrial Electronics, vol. 38, no. 6, pp. 428-437, Dec. 1991, doi: 10.1109/41.107098.

[30] H. Habibi, H. Rahimi Nohooji and I. Howard, "Adaptive PID Control of Wind Turbines for Power Regulation With Unknown Control Direction and Actuator Faults," in IEEE Access, vol. 6, pp. 37464-37479, 2018, doi: 10.1109/ACCESS.2018.2853090. 
[31] Man Gyun Na, "Auto-tuned PID controller using a model predictive control method for the steam generator water level," in IEEE Transactions on Nuclear Science, vol. 48, no. 5, pp. 1664-1671, Oct. 2001, doi: 10.1109/23.960354.

[32] G. Wang, J. Kuang, N. Zhao, G. Zhang and D. Xu, "Rotor Position Estimation of PMSM in Low-Speed Region and Standstill Using Zero-Voltage Vector Injection," in IEEE Transactions on Power Electronics, vol. 33, no. 9, pp. 7948-7958, Sept. 2018, doi: 10.1109/TPEL.2017.2767294.

[33] M. Depenbrock, "Direct self-control (DSC) of inverter-fed induction machine," in IEEE Transactions on Power Electronics, vol. 3, no. 4, pp. 420-429, Oct. 1988, doi: 10.1109/63.17963.

[34] F. Niu, K. Li and Y. Wang, "Direct Torque Control for Permanent-Magnet Synchronous Machines Based on Duty Ratio Modulation," in IEEE Transactions on Industrial Electronics, vol. 62, no. 10, pp. 6160-6170, Oct. 2015, doi: 10.1109/TIE.2015.2426678.

[35] M. H. Vafaie, B. Mirzaeian Dehkordi, P. Moallem and A. Kiyoumarsi, "A New Predictive Direct Torque Control Method for Improving Both Steady-State and Transient-State Operations of the PMSM," in IEEE Transactions on Power Electronics, vol. 31, no. 5, pp. 3738-3753, May 2016, doi: 10.1109/TPEL.2015.2462116.

[36] Y. A. I. Mohamed, "Direct Instantaneous Torque Control in Direct Drive Permanent Magnet Synchronous Motors—a New Approach," in IEEE Transactions on Energy Conversion, vol. 22, no. 4, pp. 829-838, Dec. 2007, doi: 10.1109/TEC.2007.895869.

[37] J. Xu, L. Xie, "A PWA approach to Takagi-Sugeno fuzzy logic systems" in Control and Estimation of Piecewise Affine Systems, pp. 169-192, 2014, https://doi.org/10.1533/9781782421627.169. 
[38] G. Dewantoro and Y. Kuo, "Robust speed-controlled permanent magnet synchronous motor drive using fuzzy logic controller," 2011 IEEE International Conference on Fuzzy Systems (FUZZ-IEEE 2011), Taipei, 2011, pp. 884-888, doi: 10.1109/FUZZY.2011.6007419.

[39] F. D. J L and V. Subbiah, "A novel fuzzy logic based robust speed controller for permanent magnet synchronous motor servo drive," TENCON 2009 - 2009 IEEE Region 10 Conference, Singapore, 2009, pp. 1-4, doi: 10.1109/TENCON.2009.5395845.

[40] J. -. Jung, Y. -. Choi, V. Q. Leu and H. H. Choi, "Fuzzy PI-type current controllers for permanent magnet synchronous motors," in IET Electric Power Applications, vol. 5, no. 1, pp. 143-152, January 2011, doi: 10.1049/iet-epa.2010.0036.

[41] Y. Kung and M. Tsai, "FPGA-Based Speed Control IC for PMSM Drive With Adaptive Fuzzy Control," in IEEE Transactions on Power Electronics, vol. 22, no. 6, pp. 2476-2486, Nov. 2007, doi: 10.1109/TPEL.2007.909185.

[42] S. Barkat, A. Tlemçani and H. Nouri, "Noninteracting Adaptive Control of PMSM Using Interval Type-2 Fuzzy Logic Systems," in IEEE Transactions on Fuzzy Systems, vol. 19, no. 5, pp. 925-936, Oct. 2011, doi: 10.1109/TFUZZ.2011.2152815.

[43] B.G.M. Vandeginste, D.L. Massart, L.M.C. Buydens, S. De Jong, P.J. Lewi, J. SmeyersVerbeke, "Chapter 44 - Artificial Neural Networks, Data Handling in Science and Technology,” Elsevier, vol. 20, part 2, 1998, pp. 649-699, doi: 10.1016/S0922$3487(98) 80054-3$.

[44] M. Imran, S. A. Alsuhaibani, "Chapter 7 - A Neuro-Fuzzy Inference Model for Diabetic Retinopathy Classification," in Intelligent Data-Centric Systems, Intelligent Data Analysis for Biomedical Applications, Academic Press, 2019, pp. 147-172, doi: 10.1016/B978-0-12815553-0.00007-0. 
[45] P. Gaur, B. Singh and A. P. Mittal, "Artificial Neural Network based Controller and Speed Estimation of Permanent Magnet Synchronous Motor," 2008 Joint International Conference on Power System Technology and IEEE Power India Conference, New Delhi, 2008, pp. 16, doi: 10.1109/ICPST.2008.4745351.

[46] Yang Yi, D. M. Vilathgamuwa and M. A. Rahman, "Implementation of an artificial-neuralnetwork-based real-time adaptive controller for an interior permanent-magnet motor drive," in IEEE Transactions on Industry Applications, vol. 39, no. 1, pp. 96-104, Jan.-Feb. 2003, doi: 10.1109/TIA.2002.807233.

[47] J. Yu, P. Shi, W. Dong, B. Chen and C. Lin, "Neural Network-Based Adaptive Dynamic Surface Control for Permanent Magnet Synchronous Motors," in IEEE Transactions on Neural Networks and Learning Systems, vol. 26, no. 3, pp. 640-645, March 2015, doi: 10.1109/TNNLS.2014.2316289.

[48] L. Sheng, G. Xiaojie and Z. Lanyong, "Robust Adaptive Backstepping Sliding Mode Control for Six-Phase Permanent Magnet Synchronous Motor Using Recurrent Wavelet Fuzzy Neural Network," in IEEE Access, vol. 5, pp. 14502-14515, 2017, doi: 10.1109/ACCESS.2017.2721459.

[49] F. Lin, K. Yang, I. Sun and J. Chang, "Intelligent position control of permanent magnet synchronous motor using recurrent fuzzy neural cerebellar model articulation network," in IET Electric Power Applications, vol. 9, no. 3, pp. 248-264, 3 2015, doi: 10.1049/ietepa.2014.0088. 
[50] F. Lin, I. Sun, K. Yang and J. Chang, "Recurrent Fuzzy Neural Cerebellar Model Articulation Network Fault-Tolerant Control of Six-Phase Permanent Magnet Synchronous Motor Position Servo Drive," in IEEE Transactions on Fuzzy Systems, vol. 24, no. 1, pp. 153-167, Feb. 2016, doi: 10.1109/TFUZZ.2015.2446535.

[51] Gaballah, M.M, "Design and Implementation of Space Vector PWM Inverter Based on a Low Cost Microcontroller,” Arab J Sci Eng 38, 3059-3070, 2013, doi: 10.1007/s13369-012$0464-2$.

[52] A. Maamoun, Y. M. Alsayed, A. Shalout, "Space-Vector PWM Inverter Feeding a Permanent-Magnet Synchronous Motor," World Academy of Science, Engineering and Technology, 2010, 65, pp. 627-631.

[53] Field Oriented Control of Permanent Magnet Synchronous Motors User's Guide- Microsemi

[54] P. Sarkar and S. Bhunia, "SVPWM based vector control of PMSM drive in delta domain," 2017 International Conference on Electrical, Computer and Communication Engineering (ECCE), Cox's Bazar, 2017, pp. 5-10, doi: 10.1109/ECACE.2017.7912869.

[55] M. Bhardwaj, "Sensored Field Oriented Control of 3-Phase Permanent Magnet Synchronous Motors,” Application Report, Texas Instruments, July 2013.

[56] S. Eriksson, "Permanent Magnet Synchronous Machines," Special Issue, Energies, MDPI, doi: 10.3390/books978-3-03921-351-1.

[57] B.-S. Jun, J.S. Park, J.-H. Choi, K.-D. Lee, C.-Y. Won, “Temperature Estimation of Stator Winding in Permanent Magnet Synchronous Motors Using $d$-Axis Current Injection,” Energies, 2018, 11, 2033, doi: 10.3390/en11082033.

[58] C. Lai, G. Feng, K. Mukherjee and N. C. Kar, "Investigations of the Influence of PMSM Parameter Variations in Optimal Stator Current Design for Torque Ripple Minimization," in 
IEEE Transactions on Energy Conversion, vol. 32, no. 3, pp. 1052-1062, Sept. 2017, doi: 10.1109/TEC.2017.2682178. 